\title{
Occurrence and distribution of microplastics-sorbed phthalic acid esters (PAEs) in coastal psammitic sediments of tropical Atlantic Ocean, Gulf of Guinea
}

\author{
Nsikak U. Benson *, Omowunmi H. Fred-Ahmadu \\ Department of Chemistry, Covenant University, Km 10 Idiroko Road, Ota, Nigeria
}

\section{H I G H L I G H T S}

- Baseline MPs pollution in littoral sediments of the Gulf of Guinea were investigated.

- Microplastic particles distribution across coastline were heterogenous and significant.

- Land-based anthropogenic activities are primary sources of microplastics.

- The total concentrations of PAEs ranged from BDL to $164.09 \mathrm{mg} / \mathrm{kg}$ dw, with variable aggregated site contents.

- DEHP, DnBP and DMP are the most dominant PAEs.

\section{G R A P H I C A L A B S T R A C T}

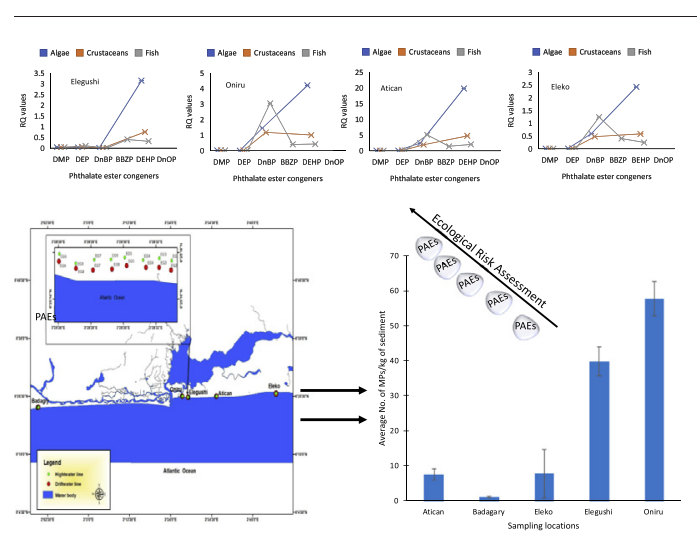

\begin{abstract}
A B S T R A C T
Baseline microplastic pollution and the occurrence, spatial distribution and ecological risk of microplastic-sorbed phthalate esters (PAEs) in littoral sandflat sediments of the Gulf of Guinea were investigated. A total of 150 sediment samples were collected using a $0.5 \times 0.5 \times 0.2 \mathrm{~m}$ quadrant placed along designated high, drift and current waterlines at five (5) beaches. Analysis for 6 PAEs-sorbed to microplastics (MPs) was carried out using gas chromatography - mass spectrometry (GC-MS). Microplastic particles (1-5 mm) were identified visually and FTIR spectroscopy was also used for identification. The MPs distribution was variably heterogenous with a total of 3424 particles per $\mathrm{m}^{2}$ found within the drift and high waterlines across all sites. Results indicated fragments as the dominant microplastic type compared to pellets and fibres. Polyethylene terephthalate was the major polymer type and accounted for a weighted average of $41 \%$ of the total plastics, followed by polystyrene (28\%), and polypropylene (21\%). The $\sum_{6}$ PAEs concentration ranged from BDL to $164.09 \mathrm{mg} / \mathrm{kg} \mathrm{dw}$, dominated by di $(2-$ ethylhexyl) phthalate (DEHP), dibutyl phthalate (DnBP), and dimethyl phthalate. The preliminary ecological risk assessment of PAEs in the microplastic fraction, $\mathrm{RQ}_{m p}$, showed DEHP and DnBP may present medium to high biological risks to marine organisms, suggesting that future study of PAEs in total sediment versus the MP fraction might be useful to refine ecological risk assessments. Land-based anthropogenic activities are primary sources of MPs, whereas oceanographic peculiarities of the area constitute the major distribution driving force.
\end{abstract} (c) 2020 Elsevier B.V. All rights reserved.

\footnotetext{
* Corresponding author at: Marine and Freshwater Biogeochemistry Research Group, Department of Chemistry, Covenant University, Ota, Ogun State, Nigeria. E-mail address: nsikak.benson@covenantuniversity.edu.ng (N.U. Benson).
} 


\section{Introduction}

Our oceans, seas, coastal and terrestrial environments are directly and indirectly riddled with billions of tons of marine debris produced from human-mediated activities. Microplastics (MPs) pollution largely involves discarded single-use everyday plastic items such as plastic bottles and straws, cotton buds, disposable diapers, fishing lines, drink stirrers, plastic containers for personal care products and medicines, Styrofoam cups, plastic grocery bags, tires, cigarette butts, textiles, plastic beverage holder, etc., which may take several hundreds of years to biodegrade once they are released into marine and terrestrial environments (Fred-Ahmadu et al., 2020; NOAA, 2015, 2018). Generally, the introduction of plastics into the aquatic ecosystem could be attributed to primary and secondary sources of pollution (Xu et al., 2020). The primary sources include the direct manufacture and introduction of the plastics into the aquatic ecosystems as well as production feedstock pellets, plastic films, resin pellets, microbeads, body scrubs, and miscellaneous plastic containers of facial products (Fred-Ahmadu et al., 2020; Xu et al., 2020; Alimi et al., 2018; Hernandez et al., 2017; Wang et al., 2017; Nizzetto et al., 2016; Rochman et al., 2015; Lechner et al., 2014; Hidalgo-Ruz et al., 2012).

More so, the secondary sources recognised as the most significant source of MPs with far-reaching health and ecological effects come from the gradual fragmentation of more abundant primary-sourced plastic materials into smaller sized particulates, through ultraviolet radiation, microbial breakdown, mechanical abrasion by wind and ocean waves, thermal degradation, and physical weathering and ageing (Xu et al., 2020; Wang et al., 2019; Eriksen et al., 2013; Barnes et al., 2009; Arthur et al., 2009). This progressive degradation process driven primarily by natural hydrological, chemical and biological factors results in the formation of plastic fragments including microplastics, generally defined as synthetic polymeric particles of diameter smaller than $5 \mathrm{~mm}$ (Fred-Ahmadu et al., 2020; NOAA, 2015, 2018; von Moos et al., 2012; Zarfl et al., 2011; Thompson et al., 2004). Other breakdown products are mesoplastics and macroplastics with diameters of 5-25 mm and greater than $25 \mathrm{~mm}$ in size, respectively.

Moreover, in recent years, increasing research attention has been focus on MPs particularly given the environmental risks and threats to aquatic organisms, primarily linked to their small size and substantial specific surface area, chemical constituents, and considerable capacity to leach out toxic organic and inorganic chemical additives including endocrine-disrupting chemical substances into the marine ecosystems, whose health risk is capable of being transferred through the food chain (Ramirez et al., 2019; Magni et al., 2018; Scopetani et al., 2018; Pérez-Lobato et al., 2016; Wang et al., 2015). Additionally, MPs have been reported to facilitate the distribution of aquatic contaminants such polycyclic aromatic hydrocarbons, organophosphorus esters, pesticides, polychlorinated biphenyls, phthalate esters, and several other persistent organic compounds (Ramirez et al., 2019; Zhang et al., 2018a; Zobkov and Esiukova, 2017; Yu et al., 2016; Qiu et al., 2015; Tanaka et al., 2013).

Phthalate esters (PAEs) are ubiquitous chemical additives, generally used as plasticizers in the manufacturing of plastics to enhance their flexibility, durability, and transparency as well as offer plastics its light weighted characteristics (Xu et al., 2020; Zhang et al., 2019; Avio et al., 2017; Kang et al., 2017; Li et al., 2017; Rahman and Brazel, 2004; IARC, 2000). Examples of PAEs include di-n-amyl phthalate (DnAP), di-n-butyl phthalate (DnBP), di-nhexylphthalate (DnHP), din-nonyl phthalate (DnNP), di-n-octyl phthalate (DnOP), di(2-nbutoxyethyl) phthalate (DBEP), butylbenzyl phthalate (BBZP), dicyclohexyl phthalate (DCHP), di-ethyl phthalate (DEP), di(2ethoxyethyl)phthalate (DEEP), di(2-ethylhexyl)phthalate (DEHP), diisobutyl phthalate (DiBP), di-methyl phthalate (DMP), di-methylglycol phthalate (DMGP), di(4-methyl-2-pentyl)phthalate (DMPP), and di (hexyl-2-ethylhexyl)phthalate (HEHP). These plasticizers are peculiarly not chemically bonded to the polymer chains of plastics, and can easily leach out into the marine ecosystems directly and consequentially from discharged phthalate-containing plastic materials (Jiménez-Skrzypek et al., 2019; Paluselli et al., 2018a; Katsikantami et al., 2016; Holahan and Smith, 2015; Fasano et al., 2015; Wang et al., 2013; NRC, 2008; ATSDR, 2001, 2002).

Phthalate esters can be generally classified as low molecular weight (LWPAEs) and high molecular weight (HWPAEs) phthalates. Considering the molecular weights of respective phthalate species, LWPAEs and HWPAEs have molecular weights that are $<250 \mathrm{~g} \mathrm{~mol}^{-1}$ and $>250 \mathrm{~g} \mathrm{~mol}^{-1}$, respectively. Low molecular weight phthalates such as DiBP, DnBP, and DEP are largely used as plasticisers in the production of packaging bags, coating materials, personal care products, nail polishes, cloves, wires and cables (NIH, 2019; Net et al., 2015; Guo et al., 2012). On the other hand, the HWPAEs including BBZP and DEHP are mostly used as plasticisers in the production of vinyl-based products (wall coverings, vinyl gloves, floor tiles, traffic cones, carpet tiles, tablecloths, furniture upholstery, shower curtains, garden hoses, etc.), medical devices (e.g. blood packaging bags, medical tubing), and building materials (NIH, 2019; Rocha et al., 2017; ATSDR, 2014).

PAEs are potentially toxic esters of phthalic acids that are uniquely responsible for disrupting the endogenous hormones in humans after exposure to extremely low concentrations, capable of resulting in behavioural and reproductive dysfunction (Prata et al., 2020; Benjamin et al., 2017; Cole et al., 2011; Diamanti-Kandarakis et al., 2009; Patisaul and Adewale, 2009; Gray Jr. et al., 2006; BKH, 2000). Endocrine-disrupting compounds (EDCs) such as some phthalate metabolites act by adversely impinging on the natural production, secretion, and metabolic activities of hormones in the human body (Diamanti-Kandarakis et al., 2009; Kavlock et al., 1996). This characteristic makes PAEs one of the potent endocrine-disrupting substances found in microplastics. For example, studies have shown that phthalates such as di(2-ethylhexyl)phthalate (DEHP), diethyl phthalate (DEP), diisobutyl phthalate (DiBP), di-n-butyl phthalate (DnBP), butylbenzyl phthalate (BBZP), and di(2-ethylhexyl)phthalate (DEHP) are capable of reproductive effects such as impeding the growth of embryos and potentially promote abortion rate and infant mortality, as well as having carcinogenic, mutagenic, and endocrine-disruptive corollaries due to exposure to these phthalates (Ramirez et al., 2019; Chen et al., 2017; López-Carrillo et al., 2010; Lee et al., 2009; Botham and Holmes, 2005). In view of the adverse eco-risks associated with DEHP, DEP, DnBP DMP, DnOP, and BBZP, the American Institute for environment and health (AIEH), the International Agency for Research on Cancer (IARC), the European Union (EU), and the United States Environmental Protection Agency (USEPA) have classified these phthalates priority pollutants (EU Parliament, 2008; Botham and Holmes, 2005; USEPA, 1982). Accordingly, several countries including the United States, EU and Canada have restricted or prohibited the use of PAEs in childcare items and toys (CPSC, 2017; USEPA, 2012, 2017; EU, 2011, 2013; HPA, 2010; Sathyanarayana, 2008; SCCP, 2007).

Esters of phthalic acids (PAEs) are widespread emerging marine pollutants that have been reported in littoral sediments of several aquatic ecosystems. MPs have been reported as potential vectors of organic contaminants, and are capable of exacerbating the bioaccumulation and potential ecotoxicity, carcinogenicity and mutagenicity of these substances in the aquatic ecosystems (Xu et al., 2020). In the marine environment, sediments are known storehouses of microplastics, and invariably potential sinks of PAEs (Arfaeinia et al., 2019; Ramzi et al., 2018; Chen et al., 2017). In particular, DEHP, DEP, DnBP, DMP, and DiBP are the most preponderant and frequently detected phthalate congeners in coastal sediments (Zhang et al., 2018a; Gao and Wen, 2016). These chemical additives could leach out of microplastics and become bioavailable to marine organisms when ingested (Ribeiro et al., 2019; Jeong et al., 2018; Kolandhasamy et al., 2018; Gray and Weinstein, 2017). Humans are primarily exposed to MPs and the associated potentially toxic inorganic and organic chemicals through ingestion, dermal contact and inhalation routes (Prata et al., 2020; Li et al., 2019; Reyes 
and Price, 2018; Arbuckle et al., 2016; Galloway, 2015; Genuis et al., 2012). Human exposure to MPs through food ingestion is believed to be the foremost route (US EPA, 2017; Calafat and McKee, 2006; Colacino et al., 2010). According to Cox et al. (2019), the estimated intake of MPs via food consumption ranged between 39,000-52,000 particles/person/year. Such exposures could inadvertently result in biological and chemical risks in humans which could be evaluated by estimations for oral ingestion (Cox et al., 2019) and the inhalation routes (Vianello et al., 2019; Prata, 2018; NRC, 2008; Otake et al., 2004; ATSDR, 2002). With regards to the adverse effects on humans, it is noteworthy to point out that there are currently no acceptable limits for the concentrations of microplastics or the degree of contamination set for PAEs in sediments. However, in recent years, PAEs in microplastics have received growing attention from researchers worldwide in a bid to further scientific knowledge on their occurrence, fate, and ecological risks in sediments and other marine matrixes.

PAEs have been widely reported in marine and terrestrial matrices, however, there is limited information available about their occurrence and distribution in coastal sediments and microplastics in aquatic ecosystems of the Gulf of Guinea. The coastline has multiple sources of human-mediated pollution, including manufacturing industries, commercial transportation, fishing, recreational hotspots, religious centres, agro-based industries, power plants, wood milling and plank markets, and petroleum tank farms. It also receives large quantities of domestic and effluents from land-based industries. Despite significant possibility of contamination in the littoral beaches and water bodies, research is largely stymied owing to limited analytical capabilities. Therefore, the objective of the present study is to determine the occurrence and concentration distribution of microplastics and phthalate esters in psammitic sediment beaches of the tropical coast of the Gulf of Guinea. Currently, there is no data are available about the MPs and PAEs concentrations in coastal sediment of the region. This report presents the baseline information on MPs and PAEs in the Gulf of Guinea. Also, the research provides for the first time, the estimated human health and ecological risks associated with PAEs in littoral sediments in the region.

\section{Materials and method}

\subsection{Study areas}

The study area comprises five beaches located along the stretch of the coastline of the Gulf of Guinea in the tropical Atlantic Ocean. The Nigeria marine area is bordered by a coastline stretching from the Cross River estuary at the east to Badagry beach in the west with a distance of about $853 \mathrm{Km}$. The coast extends from the low water line to about $15 \mathrm{Km}$ inland in the west to about $150 \mathrm{Km}$ in the oil rich Niger Delta, and about $35 \mathrm{Km}$ in the eastern areas of Cross River (Benson, 2010a; Awosika and Folorunsho, 2006; Ibe, 1990). The Atlantic coastline is made up of highly varied geomorphologic characteristics that are very vulnerable to climate change and pollution (Benson et al., 2015, 2017, 2018; Ajao and Anurigwo, 2002; Awosika, 1995). It is fronted by the Gulf of Guinea with about 22 estuaries and several rivers and rivulets discharging into several aquatic ecosystems such as the Lagos lagoon, Niger Delta, Imo River, Qua Iboe River, and the Cross River. It is composed of low-lying coastal areas made up of a barrier lagoon complex, low-lying Mahin mud coast, the Niger Delta and the easternmost lowlying Strand coast.

The entire Nigerian coastal area is divided into four main geomorphic units including the Barrier lagoon coast which lies between Badagry and Ajumo east of Lekki town; the Mahin mud coast lies between Ajumo and the Benin river-estuary in the northwestern flank of the Niger Delta; and the Niger Delta is sandwiched between Imo river in the east and Benin river in the west; and the Strand coastline lies between Imo river and the Nigeria/Cameroun border in the east with the Cross River inclusive (Benson, 2010b; Adesina et al., 2008). The coastal areas in general experience the tropical wet climatic period (April to October) with annual mean temperatures between 25 and $28{ }^{\circ} \mathrm{C}$, and dry climate (November to March) conditions with mean temperatures of about 29 to $32{ }^{\circ} \mathrm{C}$. The seasons are marked by relatively high monthly rainfall of above $400 \mathrm{~mm}$ during the wet season, and between 100 and $250 \mathrm{~mm}$ during the dry season (French et al., 1995). The Nigerian coastline is characterized by a mixture of sandy, silty and muddy deposits (Benson, 2010b).

The beaches designated for sampling were Badagry (BG), Oniru (OR), Elegushi (EG), Atican (AC) and Eleko (EK), while the lagoon locations included a site close to the US Embassy (UE), National Institute of Oceanography and Marine Research (NIOMR) jetty (NR), and University of Lagos waterfront (UL). The coordinates of each sampling location on the coast was recorded using a handheld Garmin ${ }^{\circledR}$ Global Positioning System (GPS) device. Information on the sampling locations are presented in Table S1a, b.

\subsection{Standards and reagents}

The PAEs standards $(2000 \mu \mathrm{g} / \mathrm{mL})$ used in this study were purchased from AccuStandard (New Haven, CT, USA). These were dimethyl phthalate (DMP), diethyl phthalate (DEP), dibutyl phthalate (DnBP), benzylbutyl phthalate (BBZP), di(2-ethylhexyl) phthalate (DEHP), and di n-octyl phthalate (DnOP) standards. The cyclohexane and ethyl acetate were GC-grade solvents purchased from ChromaSolv ${ }^{\mathrm{TM}}$ (Charlotte, NC, USA). All glass jars and glassware were prewashed with Ultrapure water, and later rinse in $10 \%$ nitric acid. Before field sampling, the stainless-steel spoons and forceps were prewashed with Ultrapure water and rinsed with a mixture of n-hexane and acetone in the laboratory.

\subsection{Beach sediment collection}

Ten sampling locations on the beach were established about $100 \mathrm{~m}$ apart from each other, using a measuring tape, making about $1 \mathrm{~km}$ stretch of the coastline. Sediment samples were collected from three transects in each location, namely: (a) The high waterline - the point that represents the maximum rise of the ocean water. It is typically composed of debris left by the high tide; (b) The drift waterline - the intersection of land with the ocean water where the water fluctuates, changing with the tide or other fluctuations in the water; and (c) The current waterline - the intersection of the land with the water surface at an elevation of low water (NOAA, 2016). Surface sediment samples were collected from the high waterline and drift line by placing a quadrant $(0.5 \times 0.5 \times 0.2 \mathrm{~m})$ on the ground, and a stainless-steel spoon was used to scoop the beach sand up to $2 \mathrm{~cm}$ depth and visible plastic debris within the quadrant. Large identifiable organic matter was removed by handpicking. Sediment samples were wrapped in aluminium foil and stored in clean Ziploc ${ }^{\mathrm{TM}}$ bags. The quadrant could not be deployed at the current waterline due to ocean surge. Sediment samples were quickly collected using stainless-steel spoon at current waterline locations along the transect of each drift and high waterline. Thirty sediment samples were collected from each beach, giving a total of 150 sediment samples from five beaches along the coastline. Each sediment sample was air-dried and sieved using stainless-steel sieves with mesh sizes $5 \mathrm{~mm}, 3 \mathrm{~mm}$ and $1 \mathrm{~mm}$. Plastics retained on the 1-5 mm sieve were separated and classified into two grain sizes, namely $\leq 3 \mathrm{~mm}$ and $\leq 1 \mathrm{~mm}$. Each sediment grain size was properly labelled and wrapped in aluminium foil.

\subsection{Extraction of beach sediment samples}

The saturated solution was prepared by dissolving $358.9 \mathrm{~g}$ of sodium chloride $(\mathrm{NaCl})$ in $1 \mathrm{~L}$ of distilled water (Bosker et al., 2018). This is because the solubility of $\mathrm{NaCl}$ is about $35 \mathrm{~g} / 100 \mathrm{~mL}$ of water at $20^{\circ} \mathrm{C}$. The sediment was carefully mixed, and $1.0 \mathrm{~kg}$ was weighed into a clean glass 
jar and extracted with saturated $\mathrm{NaCl}$ solution in portions of about $200 \mathrm{~g}$ by grain size and thoroughly mixed using a glass stirring rod. The mixture was then placed on an orbital shaker and agitated at $300 \mathrm{rpm}$ for $15 \mathrm{~min}$. The mixture was allowed to settle for $1 \mathrm{~h}$, and the supernatant was filtered using a $1 \mathrm{~mm}$ mesh stainless steel sieve. The residues comprised of materials with densities lower than the saturated $\mathrm{NaCl}$, microplastics, and organic matter. The procedure was repeated two more times to in order to optimize the removal of all microplastics (Vianello et al., 2019). The retained materials in the sieve were rinsed with distilled water and air dried at room temperature of $28^{\circ} \mathrm{C}$.

\subsection{Fourier transform infrared spectrometry (FTIR) analysis}

FTIR analysis was performed on all MPs samples collected. The infrared (IR) spectrum of each sample was recorded in single reflection mode using the Agilent Cary 630 FTIR Spectrometer equipped with a Diamond attenuated total reflectance (ATR) system and connected to an Agilent MicroLab PC Software. The single-refection type Ila diamond crystal has a $1 \mathrm{~mm}$ diameter sampling surface with a $200 \mu \mathrm{m}$ active area and provides approximately $2 \mu \mathrm{m}$ depth of penetration for IR energy at $1700 \mathrm{~cm}^{-1}$. The FTIR analysis was performed with 32 scans per replicate in the range of 4000 to $650 \mathrm{~cm}^{-1}$ at a resolution of $2 \mathrm{~cm}^{-1}$.

\subsection{Samples pretreatment and extraction of MPs-sorbed PAES}

After FTIR characterization, $5 \mathrm{~mL}$ of a mixture of cyclohexane (CHX) and ethyl acetate (EA), in the ratio 1:1 was added to each microplastic sample $(0.25-0.5 \mathrm{~g})$ in amber glass vials, previously rinsed with CHX: $\mathrm{AE}(1: 1)$. The vials were vigorously shaken on a vortex machine and placed in an ultrasonic bath for $20 \mathrm{~min}$. Then the samples were placed on an orbital rotator for $24 \mathrm{~h}$ to allow the samples to soak in the solvent. After centrifugation, the extract was transferred to a new vial, and the extraction process was repeated two more times. After $72 \mathrm{~h}$, a total volume of $15 \mathrm{~mL}$ had been recovered which contained the PAE congeners adsorbed to the plastics (Camacho et al., 2019). The extract was concentrated to $1 \mathrm{~mL}$, transferred to amber GC vials and stored in the fridge at 4 ${ }^{\circ} \mathrm{C}$ prior to GC-Q-MS analysis.

\subsection{GC-Q-MSD instrumentation}

Each analysis for PAEs was performed using an Agilent 7890A gas chromatograph coupled with a mass selective detector (Agilent 5975C) with a HP-5 capillary column coated with $5 \%$ phenyl methyl siloxane with dimensions $25 \mathrm{~m} \times 320 \mu \mathrm{m} \times 0 \mu \mathrm{m}$ (Agilent Technologies, Avondale, PA, United States). The GC-Q-MSD operational control conditions are presented in Table S2. In order to quantify and identify individual PAEs congeners using the GC-Q-MSD, a standard (AccuStandard $₫$ M-8060 Phthalate Esters Mix) in $2000 \mu \mathrm{g} / \mathrm{mL}$ including a combination of dimethyl phthalate, diethyl phthalate, dibutyl phthalate, benzyl butyl phthalate, di(2-ethylhexyl) phthalate, and di-n-octyl phthalate was used. Summary information for the six phthalate esters considered in the present study is presented in Table S3, Fig. S1. The concentrations of MP-sorbed PAEs were expressed on a dry weight ( $\mathrm{dw}$ ) basis of the microplastics.

\subsection{Quality control and quality assurance}

In order to calibrate the GC-Q-MSD, a seven (7) point calibration curve was prepared for each calibration standards (dimethyl phthalate, diethyl phthalate, dibutyl phthalate, benzyl butyl phthalate, di(2ethylhexyl) phthalate, and di-n-octyl phthalate) after serial dilution of $2000 \mu \mathrm{g} / \mathrm{mL}$ standard stock solutions into $5.0 \mu \mathrm{g} / \mathrm{mL}, 10.00 \mu \mathrm{g} / \mathrm{mL}$, $20.00 \mu \mathrm{g} / \mathrm{mL}, 30.00 \mu \mathrm{g} / \mathrm{mL}, 50.00 \mu \mathrm{g} / \mathrm{mL}, 80.00 \mu \mathrm{g} / \mathrm{mL}$, and 100.00 $\mu \mathrm{g} / \mathrm{mL}$. The PAEs calibration curves indicated correlation coefficients ranging from 0.995 to 0.997 . Also, reagent blanks and procedural blanks (P-blanks) were prepared and analysed to check the instrument's optimal and sensitivity conditions. The detection limits of the analytical method or method detection limits (MDLs) were evaluated using the Pblanks, and calculated as the signal-to-noise ratio of 3. The MDLs ranged from 0.06 to $6.01 \mu \mathrm{g} / \mathrm{mL}$, and the concentrations were normalised using the blanks by subtracting from each sample. Additionally, in order to check the reliability of the analytical measurements and validation of measured variables in relation to their accuracy and precision, $0.3 \mathrm{~g}$ of samples were spiked with $50 \mu \mathrm{L}$ of surrogate standards and extracted following the same procedure as the sample. The aliquots were concentrated to $1 \mathrm{~mL}$ and collected in amber GC vials, and their relative recoveries were evaluated following analysis in duplicates. The recoveries of the PAEs ranged from $93.6 \%$ to $115.0 \%$ from spiked surrogate MPs samples. In addition, meticulous attention was taken in order to avoid deliberate cross-contamination from laboratory items such as plastic labwares and gloves that might have resulted in enhanced background concentrations of the phthalates.

\subsection{Evaluation of ecological risks}

The relative risk of microplastics-sorbed PAEs associated with coastal sediments was evaluated using the risk quotient $\left(\mathrm{RQ}_{\text {sed }}\right)$ method proposed by the European Commission technical guidance document (TGD) on risk assessment (EC, 2003). In this study, the TGD risk quotient was used as indicator for the relative level of ecological concern for the MP fraction, but was not applied to total sediment concentration. Thus, an index, $\mathrm{RQ}_{m p}$, specific to microplastic fraction was calculated for three organisms considered in the present study using the ratio of measured concentration $\left(\mathrm{MC}_{P A E}\right.$ ) of each PAE congener to the predicted noeffect concentration (PNEC), as indicated in Eq. (1):

$R Q_{m p}=\frac{M C_{P A E}}{P N E C}$

where $M C_{P A E}$ is the measured MPs-sorbed PAEs concentration separated from sediments. The toxicity data, PNEC values of the sorbed phthalates in plastics isolated from sediment samples and other relevant information are presented in the Supporting information (Section 1 and Table S12). According to the model adopted for assessment of risk to organisms in aquatic ecosystems, the $\mathrm{RQ}_{m p}$ values were classified into three grades: high risk $\left(\mathrm{RQ}_{m p}>1\right)$, medium risk $\left(0.01<\mathrm{RQ}_{m p}\right.$ $<1)$, and low or no risk $\left(\mathrm{RQ}_{m p}<0.01\right)$, respectively.

On the other hand, the phthalate pollution index (PPI) was computed using the Tomlinson's pollution load approach (Tomlinson et al., 1980) as reported by Benson et al. (2018). The PPI was calculated according to Eq. 2:

$P P I=\left[C F_{1} \times C F_{2} \times C F_{3} \times C F_{4} \ldots \ldots \ldots \times C F_{n}\right]^{1 / n}$

where $\mathrm{n}$ is the number of phthalates $(\mathrm{n}=6), \mathrm{CF}_{n}$ is the concentration of PAEs congeners in the sediment samples. The calculated PPI represents the cumulative degree of phthalates contamination in microplastic particles of the sediment samples.

\section{Results and discussion}

\subsection{Concentrations of microplastics}

The results indicate the concentration of MPs in psammitic sediment samples $(n=150)$ of the coastline showed variable distribution with a total of 3424 particles $/ \mathrm{m}^{2}$ within the drift and high waterlines across all sites (Fig. 1). The highest number of MPs was found at the EG and OR sites with 1196 particles $/ \mathrm{m}^{2}$ and 1730 particles $/ \mathrm{m}^{2}$, while the site BG recorded the lowest MPs with 36 particles $/ \mathrm{m}^{2}$. The enhanced concentration of MPs at the EG and OR sites may be attributed to the proximity of these locations to industries, recreation and tourist hotspots, trading and religious activities, shops, bars, and residential areas, where piles of 
plastic litters are indiscriminately discarded by humans, and transported and distributed along the coast by ocean waves (Benson et al., 2014). The comparatively low amount of microplastic particles at Badagry (BG) site could be attributed to the routine sanitary management practices by small scale businesses located around the beach. However, about 684.8 particles $/ \mathrm{m}^{2}$ was obtained as the weighted amount of MPs accumulated at all sites along the oceanic coastline of the study area. In general, the extracted microplastics indicated variability in terms of colour, type of plastic, abundance, shape and weight.

Most of the MPs found were fragments of various plastic types, fibres, ropes and pellets, which fingerprints their origins, composition and polymeric structure as products of progressive degradation of larger primary plastic materials into smaller sized particles. Evidently, most MPs were round and cylindrical pellets and fragments of different shapes of colours such as yellow, white, green, black, green, brown, purple, etc. The majority of MPs in the beach samples were mainly found in the high and drift waterlines, while MPs were characteristically not present in sediment samples obtained from the current waterline. In addition, the MPs were classified according to physical types and confirmed polymer types (Fig. 2). The results indicated that polyethylene terephthalate accounted for an average of $41 \%$ of total plastics, followed by polystyrene $(28 \%)$, polypropylene $(21 \%)$, polyurethane $(3 \%)$, polyamide (5\%), ethyl vinyl acetate (1\%), and polyethylene (0.5\%) (Fig. 3). The accumulation of these large amounts of MPs could be associated with anthropogenic and industrial activities found along the coastline.

\subsection{Occurrence and concentrations of microplastic-sorbed PAEs in coastal sediments}

Six (6) phthalate esters (dimethyl phthalate (DMP), diethyl phthalate (DEP), dibutyl phthalate (DnBP), benzylbutyl phthalate (BBZP), di (2-ethylhexyl) phthalate (DEHP), and di n-octyl phthalate (DnOP)) were detected by the GC-Q-MSD in all samples analysed, indicating the prevalence distribution of PAEs in the microplastic samples collected from the study area. The concentrations of phthalate esters sorbed to microplastics of beach sediments in the Gulf of Guinea and the weighted levels ( $\sum_{6} \mathrm{PAEs}$ ) and phthalate pollution index (PPI) are presented in Tables $1 \mathrm{a}$ and $1 \mathrm{~b}$. The total concentrations of individual PAE congeners were found between BDL and $164.09 \mathrm{mg} / \mathrm{kg} \mathrm{dw}$, with aggregated site concentrations of $51.99 \pm 14.89,60.82 \pm 20.31,118.02 \pm$ $42.68,15.98 \pm 5.18,177.02 \pm 66.14$, and $69.10 \pm 25.56 \mathrm{mg} / \mathrm{kg} \mathrm{dw}$ for AC, EG, OR, EK, UE, and NR locations, respectively (Tables S4-10). The samples from the Oniru and Lagos lagoon sites indicated microplastics-sorbed phthalic acid esters (PAEs) with the highest concentrations (Fig. 4).

The most prevalent phthalate esters were di(2-ethylhexyl) phthalate and dibutyl phthalate, with the former having a detection frequency (DF) between $70.11 \%$ at the Atican site and $92.69 \%$ at the Lagos lagoonal ecosystem. Also, the detection frequency of dibutyl phthalate (DnBP) ranged between $0.16 \%$ and $18.49 \%$ at AC and EK sites, respectively. In general, the weighted DF of dimethyl phthalate, diethyl phthalate, dibutyl phthalate, benzylbutyl phthalate, di(2-ethylhexyl) phthalate, and di-n-octyl phthalate in coastal sediment samples were $4.92 \%$, $0.10 \%, 9.80 \%, 0.14 \%, 84.93 \%, 0.10 \%$, respectively (Table S11). According to the results presented in Table S11, DEHP, DnBP and DMP were the most frequently detected esters in the microplastic samples investigated, contributing $84.93 \%, 9.80 \%$, and $4.92 \%$, respectively, to the total phthalate ester species found in the psammitic sediments collected along the littoral beaches of the Gulf of Guinea. DEHP and DnBP have been reported as preponderant environmental contaminants that pose serious biological and health risks. They are generally produced and extensively used as plasticisers for polyvinyl chloride (PVC) and non-PVC materials mainly found in applications such as the manufacturing of building materials, medical devices and consumer household products (NIH, 2019; ATSDR, 2014; IARC, 2014).

The site UE MPs-associated with the coastal sediments indicated the highest concentration of DEHP ( $164.09 \mathrm{mg} / \mathrm{kg} \mathrm{dw}$ ) followed by DnBP with $12.37 \mathrm{mg} / \mathrm{kg} \mathrm{dw}$; whereas, the least detected PAE congener concentration was recorded as $0.11 \mathrm{mg} / \mathrm{kg} \mathrm{dw}$ for DnOP. However, a comparably low concentrations of DEHP, 12.97 and $36.45 \mathrm{mg} / \mathrm{kg} \mathrm{dw}$, were

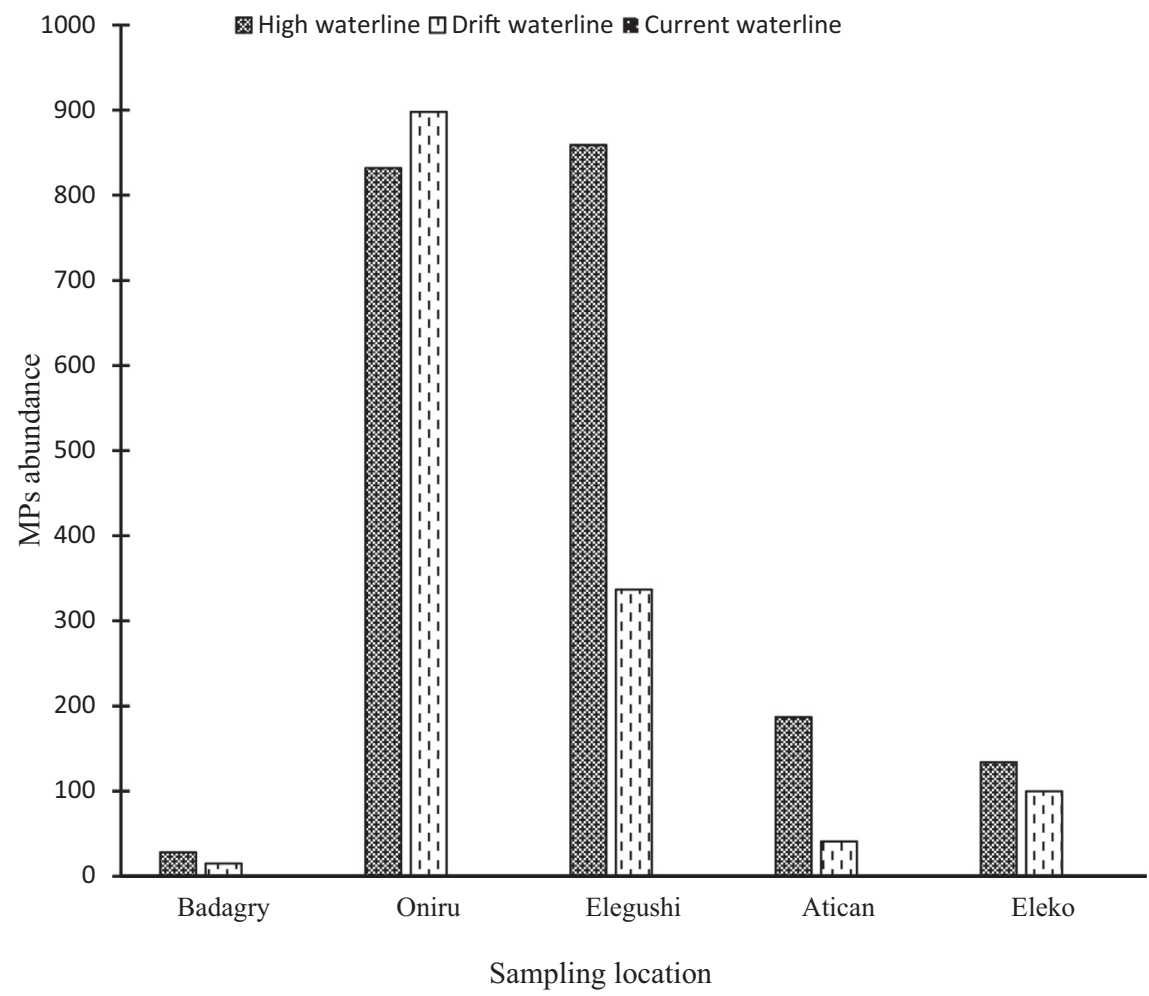

Fig. 1. Microplastic relative abundance (particles $/ \mathrm{m}^{2}$ ) based on tidal waterline. 


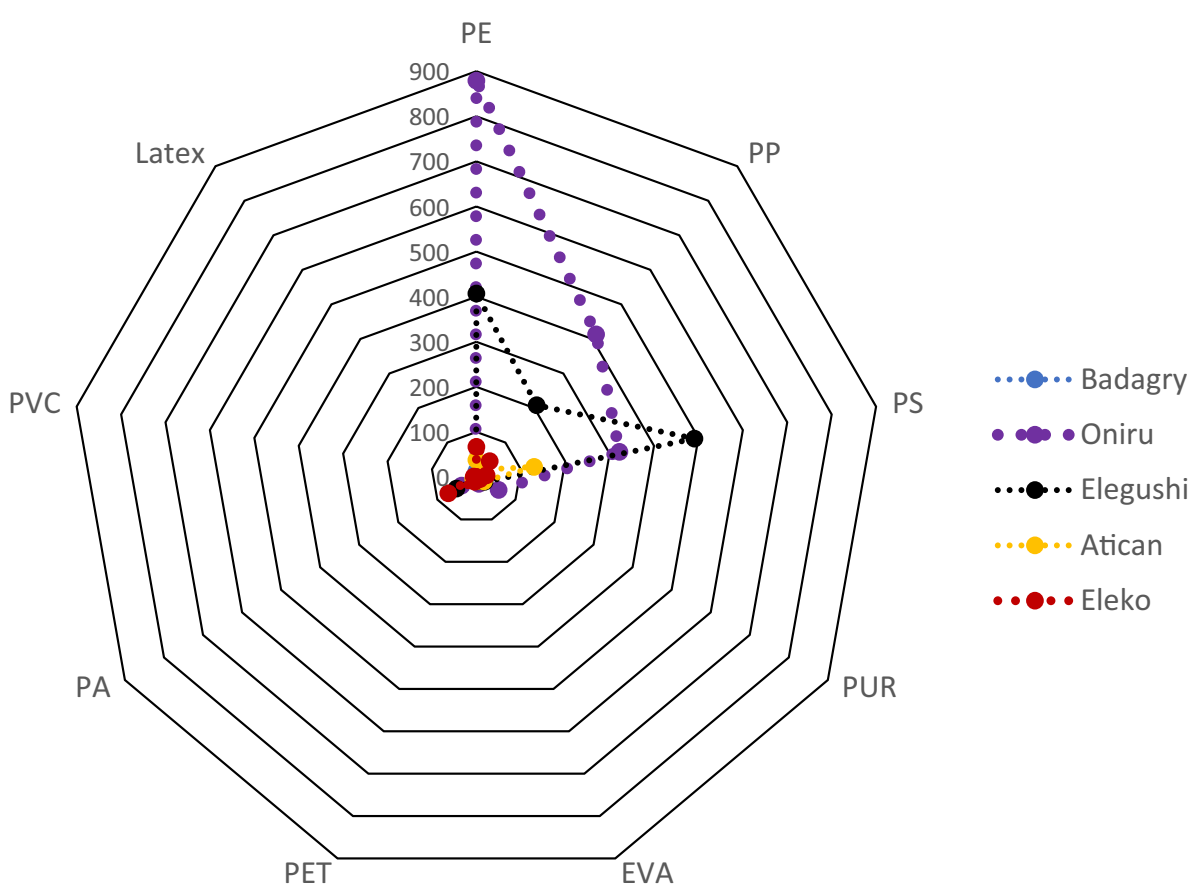

Fig. 2. Relative abundance of polymeric types of microplastics at all sites.
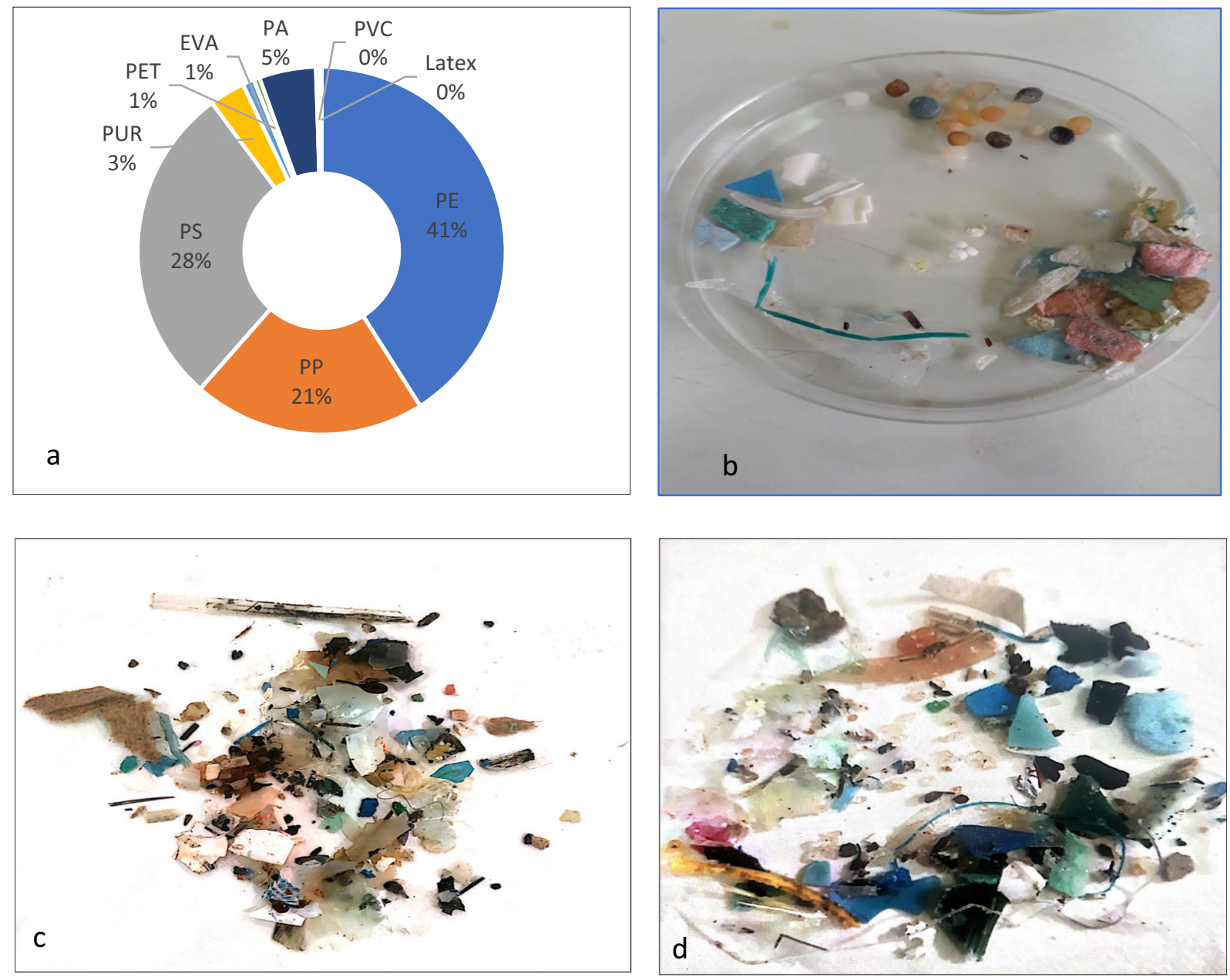

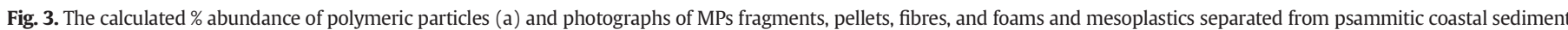
samples (b-d) 
Table 1a

Mean concentrations ( $\mathrm{mg} / \mathrm{kg}$ ) of MPs-sorbed PAEs congeners and phthalate pollution index.

\begin{tabular}{|c|c|c|c|c|c|c|c|c|c|}
\hline \multicolumn{2}{|c|}{ Location/sample code } & \multirow{2}{*}{$\begin{array}{l}\text { DMP } \\
-\end{array}$} & \multirow{2}{*}{$\begin{array}{l}\text { DEP } \\
0.03 \pm 0.00\end{array}$} & \multirow{2}{*}{$\frac{\mathrm{DnBP}}{-}$} & \multirow{2}{*}{$\begin{array}{l}\text { BBZP } \\
-\end{array}$} & \multirow{2}{*}{$\begin{array}{l}\text { DEHP } \\
9.34 \pm 0.52\end{array}$} & \multirow{2}{*}{$\begin{array}{l}\text { DnOP } \\
-\end{array}$} & \multirow{2}{*}{$\frac{\sum_{6} \mathrm{PAES}}{9.37}$} & \multirow{2}{*}{$\begin{array}{l}\text { PPI } \\
0.53\end{array}$} \\
\hline Elegushi & $\mathrm{EHH}$ & & & & & & & & \\
\hline & EDC & $0.01 \pm 0.00$ & $0.01 \pm 0.00$ & $1.56 \pm 0.36$ & $0.01 \pm 0.00$ & $7.44 \pm 0.03$ & $0.13 \pm 0.03$ & 9.16 & 0.11 \\
\hline & $\mathrm{EHC}$ & $0.02 \pm 0.01$ & - & $1.83 \pm 0.08$ & $0.01 \pm 0.00$ & $6.21 \pm 0.01$ & - & 8.06 & 0.20 \\
\hline & EDF & $0.01 \pm 0.00$ & - & $1.53 \pm 0.03$ & $0.02 \pm 0.00$ & $6.54 \pm 0.09$ & $0.01 \pm 0.00$ & 8.11 & 0.11 \\
\hline & EDH & - & - & $1.55 \pm 0.05$ & $0.02 \pm 0.00$ & $8.83 \pm 0.11$ & $0.01 \pm 0.00$ & 10.4 & 0.23 \\
\hline & EDP & $0.01 \pm 0.00$ & $0.05 \pm 0.00$ & $1.63 \pm 0.12$ & - & $6.22 \pm 0.28$ & 0.01 & 7.92 & 0.14 \\
\hline & EHF & - & - & - & $0.01 \pm 0.00$ & $1.05 \pm 0.06$ & - & 1.06 & 0.10 \\
\hline & EHP & - & $0.01 \pm 0.00$ & $1.46 \pm 0.08$ & $0.03 \pm 0.00$ & $5.25 \pm 0.04$ & - & 6.75 & 0.22 \\
\hline \multirow[t]{8}{*}{ Oniru } & ODC & $0.02 \pm 0.00$ & $0.02 \pm 0.00$ & $1.02 \pm 0.00$ & $0.04 \pm 0.00$ & $19.09 \pm 0.00$ & $0.03 \pm 0.00$ & 20.22 & 0.15 \\
\hline & $\mathrm{OHC}$ & - & $0.02 \pm 0.00$ & $4.555 \pm 0.25$ & $0.03 \pm 0.00$ & $45.32 \pm 0.46$ & $0.11 \pm 0.00$ & 50.03 & 0.42 \\
\hline & ODF & $0.01 \pm 0.00$ & - & $1.15 \pm 0.06$ & $0.01 \pm 0.00$ & $8.21 \pm 0.28$ & - & 9.38 & 0.18 \\
\hline & $\mathrm{ODH}$ & $0.01 \pm 0.00$ & $0.01 \pm 0.01$ & $3.04 \pm 0.04$ & $0.02 \pm 0.00$ & $8.02 \pm 0.02$ & $0.01 \pm 0.00$ & 11.11 & 0.09 \\
\hline & ODR & $0.00 \pm 0.00$ & $0.04 \pm 0.02$ & $1.47 \pm 0.04$ & - & $6.80 \pm 0.00$ & - & 8.30 & 0.70 \\
\hline & $\mathrm{OHF}$ & $0.01 \pm 0.00$ & - & - & $0.02 \pm 0.00$ & $3.18 \pm 0.10$ & - & 3.21 & 0.08 \\
\hline & $\mathrm{OHH}$ & $0.01 \pm 0.00$ & $0.01 \pm 0.00$ & - & $0.01 \pm 0.07$ & $11.18 \pm 0.11$ & $0.01 \pm 0.00$ & 11.22 & 0.04 \\
\hline & OHR & $0.01 \pm 0.00$ & $0.01 \pm 0.01$ & - & $0.01 \pm 0.00$ & $4.52 \pm 0.04$ & - & 4.55 & 0.05 \\
\hline \multirow[t]{6}{*}{ Atican } & $\mathrm{ADF}$ & $15.09 \pm 0.10$ & $0.01 \pm 0.01$ & - & $0.02 \pm 0.00$ & $6.64 \pm 0.10$ & $0.01 \pm 0.00$ & 21.76 & 0.16 \\
\hline & $\mathrm{ADH}$ & $0.08 \pm 0.00$ & - & $1.02 \pm 0.07$ & $0.02 \pm 0.01$ & $7.87 \pm 0.14$ & $0.08 \pm 0.00$ & 8.12 & 0.13 \\
\hline & $\mathrm{AHF}$ & - & $0.01 \pm 0.01$ & - & $6.22 \pm 0.47$ & $4.13 \pm 0.12$ & - & 4.15 & 0.07 \\
\hline & $\mathrm{AHH}$ & - & $0.01 \pm 0.01$ & $1.8 \pm 0.12$ & - & $7.61 \pm 0.36$ & - & 7.62 & 0.07 \\
\hline & $\mathrm{ADC}$ & $0.05 \pm 0.00$ & $0.03 \pm 0.01$ & - & $0.01 \pm 0.01$ & $4.88 \pm 0.16$ & $0.01 \pm 0.01$ & 5.00 & 0.06 \\
\hline & $\mathrm{AHC}$ & - & - & - & $0.01 \pm 0.01$ & $5.33 \pm 0.04$ & $0.01 \pm 0.01$ & 5.35 & 0.08 \\
\hline \multirow[t]{5}{*}{ Eleko } & KDF & - & $0.01 \pm 0.01$ & $0.26 \pm 0.00$ & - & $2.79 \pm 0.21$ & $0.01 \pm 0.00$ & 3.07 & 0.09 \\
\hline & $\mathrm{KDH}$ & - & - & $0.01 \pm 0.01$ & $0.01 \pm 0.00$ & $0.20 \pm 0.04$ & - & 0.21 & 0.02 \\
\hline & $\mathrm{KHC}$ & - & - & $0.01 \pm 0.01$ & $0.01 \pm 0.00$ & $0.43 \pm 0.02$ & - & 0.44 & 0.03 \\
\hline & KHF & - & - & $1.10 \pm 0.01$ & $0.01 \pm 0.00$ & $4.67 \pm 0.00$ & - & 5.78 & 0.37 \\
\hline & $\mathrm{KHH}$ & - & - & $1.59 \pm 0.04$ & - & $4.89 \pm 0.07$ & - & 6.48 & 2.78 \\
\hline \multirow[t]{4}{*}{ Pristine } & PRB & $0.01 \pm 0.00$ & $0.01 \pm 0.00$ & $1.14 \pm 0.04$ & - & $4.46 \pm 0.57$ & $0.01 \pm 0.00$ & 5.63 & 0.09 \\
\hline & PRF & $0.01 \pm 0.00$ & $0.01 \pm 0.00$ & $1.25 \pm 0.28$ & $0.01 \pm 0.00$ & $7.81 \pm 0.14$ & - & 9.09 & 0.10 \\
\hline & PRH & - & - & $0.90 \pm 1.27$ & - & $5.57 \pm 0.15$ & - & 6.47 & 2.24 \\
\hline & PRS & $0.01 \pm 0.00$ & $0.01 \pm 0.00$ & $2.21 \pm 0.01$ & $0.02 \pm 0.00$ & $45.65 \pm 0.33$ & $0.01 \pm 0.00$ & 47.91 & 0.11 \\
\hline
\end{tabular}

PPI $=$ phthalate pollution index.

found in microplastics obtained from the EK and AC sites, respectively. On the other hand, the EG, NR, and OR sites had relatively enhanced concentrations of DEHP. However, the levels of DEP, DMP, BBZP, and DnOP were found at comparably low amounts. Among the 6 PAEs considered, DEHP, DnBP and DMP were the most dominant PAEs and this finding is consistent with similar reports conducted in other parts of the world (Zhang et al., 2018a,b; Li et al., 2017; Yu et al., 2016; Zheng et al., 2014; Sha et al., 2007). Their occurrence and detection prevalence of these three kinds of phthalate esters could be attributed to the fact that these plasticizers have large-scale applications in plastics manufacturing (Fred-Ahmadu et al., 2020; Sun et al., 2018; Xu et al., 2009). Overall, the weighted microplastic-sorbed PAEs levels in beach sediments at the investigated sites were largely indicative of the degree of human-mediated activities linked with the coastal ecosystems, the hydrological dynamics of the coastal zone, the discharge of untreated solid industrial and domestic wastes, and eventual transportation to the coastal sites, sediment chemistry, and type of sedimentary materials (Ramirez et al., 2019; Zhang et al., 2018b; Retama et al., 2016).

\subsection{Relationship between $\Sigma$ PAEs and microplastics}

The PAEs composition of microplastics in the sandy sediment samples of the Atlantic Ocean varied widely with the different sampling sites. However, the current investigation also explored the statistical relationship between the $\Sigma$ PAEs concentrations in the sediment samples of the sandflats and the quantity of each microplastics (particles $/ \mathrm{m}^{2}$ ) across all sites. The result presented in Fig. 5 indicates that the total MPs particles exhibited a significant positive correlation with the PAEs (DMP, DEP, DBP, BBZP, DEHP, and DnOP) concentrations ( $\mathrm{r}=0.4, p<$ 0.05 ), and were heterogeneously distributed across all sites. A positive trend in the relationship between the amount of MPs and the $\mathrm{P} A \mathrm{AES}$ concentrations across the various sites for all the MPs types may be

Table 1b

Mean concentrations ( $\mathrm{mg} / \mathrm{kg}$ ) of MPs-sorbed PAEs congeners and phthalate pollution index in Lagos lagoon samples.

\begin{tabular}{|c|c|c|c|c|c|c|c|c|c|}
\hline \multicolumn{2}{|c|}{ Location/sample code } & \multirow{2}{*}{$\frac{\text { DMP }}{-}$} & \multirow{2}{*}{$\begin{array}{l}\text { DEP } \\
0.01 \pm 0.00\end{array}$} & \multirow{2}{*}{$\begin{array}{l}\text { DnBP } \\
1.71 \pm 0.02\end{array}$} & \multirow{2}{*}{$\frac{\text { BBZP }}{0.02 \pm 0.00}$} & \multirow{2}{*}{$\begin{array}{l}\text { DEHP } \\
10.25 \pm 0.34\end{array}$} & \multirow{2}{*}{$\frac{\mathrm{DnOP}}{-}$} & \multirow{2}{*}{$\frac{\sum_{6} \text { PAEs }}{11.99}$} & \multirow{2}{*}{$\frac{\text { PPI }}{0.56}$} \\
\hline Lagos lagoon & $\mathrm{CNI}$ & & & & & & & & \\
\hline & CUN & $0.09 \pm 0.00$ & $0.03 \pm 0.00$ & $0.89 \pm 0.02$ & $0.03 \pm 0.00$ & $11.23 \pm 0.39$ & $0.01 \pm 0.00$ & 12.28 & 0.14 \\
\hline & CUS & $0.01 \pm 0.00$ & $0.04 \pm 0.00$ & $1.51 \pm 0.06$ & $0.01 \pm 0.00$ & $21.20 \pm 0.01$ & $0.01 \pm 0.00$ & 22.78 & 0.10 \\
\hline & NIF & - & $0.05 \pm 0.01$ & $1.59 \pm 0.00$ & $0.02 \pm 0.00$ & $14.16 \pm 0.05$ & - & 15.82 & 0.40 \\
\hline & $\mathrm{NIH}$ & - & - & $0.97 \pm 0.04$ & - & $4.50 \pm 0.07$ & $0.01 \pm 0.00$ & 5.48 & 0.35 \\
\hline & NIS & $0.01 \pm 0.00$ & - & $0.57 \pm 0.08$ & $0.01 \pm 0.00$ & $10.66 \pm 0.13$ & - & 11.25 & 0.16 \\
\hline & UNF & - & $0.03 \pm 0.00$ & $0.44 \pm 0.62$ & $0.02 \pm 0.00$ & $5.48 \pm 0.05$ & - & 5.97 & 0.19 \\
\hline & UNH & $0.01 \pm 0.00$ & - & $1.59 \pm 0.08$ & - & $15.52 \pm 0.49$ & $0.03 \pm 0.04$ & 17.15 & 0.29 \\
\hline & UNS & - & - & $0.89 \pm 0.01$ & $0.01 \pm 0.00$ & $17.57 \pm 0.34$ & $0.03 \pm 0.00$ & 18.5 & 0.26 \\
\hline & UNF & - & - & - & $0.01 \pm 0.00$ & $4.66 \pm 0.10$ & $0.01 \pm 0.00$ & 4.68 & 0.08 \\
\hline & USH & - & - & $2.20 \pm 0.21$ & $0.02 \pm 0.00$ & $35.38 \pm 0.73$ & - & 37.6 & 1.16 \\
\hline & USS & $0.01 \pm 0.00$ & - & $0.01 \pm 0.00$ & $0.01 \pm 0.00$ & $13.48 \pm 0.00$ & $0.01 \pm 0.00$ & 13.52 & 0.04 \\
\hline
\end{tabular}

PPI $=$ phthalate pollution index. 


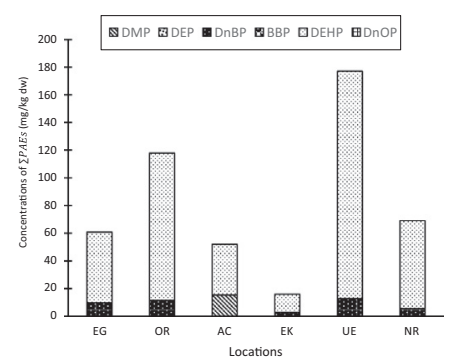

Fig. 4. Concentrations of sum MPs-sorbed PAEs determined in sediment samples along the coast of Gulf of Guinea.

due to the sedimentation and hydrodynamic peculiarities of the coastal zones, as well as the weathering characteristics of the microplastics. Previous studies have reported the relationship between microplastic types and the enhanced PAEs concentrations as a function of the rate of weathering associated with solar radiation and high beach temperatures (Zhang et al., 2018a,b,c; Andrady, 2011; Corcoran et al., 2009).

A previous report by Zhang et al. (2019) indicated that the relationship between microplastics and PAEs (DEP, DDP, DiBP, DMP, and DPhP) concentrations was attributed to the non-point MPs sources including leaching and aeolian deposition, whose particles distribution were primarily driven by seamount-current interactions. A similar report by Ramirez et al. (2019) indicates a positive correlation between the amount of microplastics found in the coastal sediment of an urban ecosystem and the phthalate esters (BBZP, DBP, DEP, DMP, DnOP, DEHP, and DEHA) concentrations, which was attributed to oceanographic characteristics of the studied ecosystem including the prevalent tidal waves and rate of sedimentation.

However, the current baseline report indicates that possible leaching of PAEs by MPs in the psammitic beaches of the tropical Atlantic Ocean might be directly linked as the potential sources of phthalate esters detected in the coastal sediment samples. Once the polymeric bonds of PAE congeners are broken down, and the surfaces of MPs including microfibres, pellets and fragments are persistently degraded and further fragmented by intense weathering activities, the concentrations of the plasticizers could be progressively leached into the aquatic and terrestrial environment (Zhang et al., 2018a,b,c; Wensing et al., 2005; Calvert and Billingham, 1979). The occurrence and concentration of

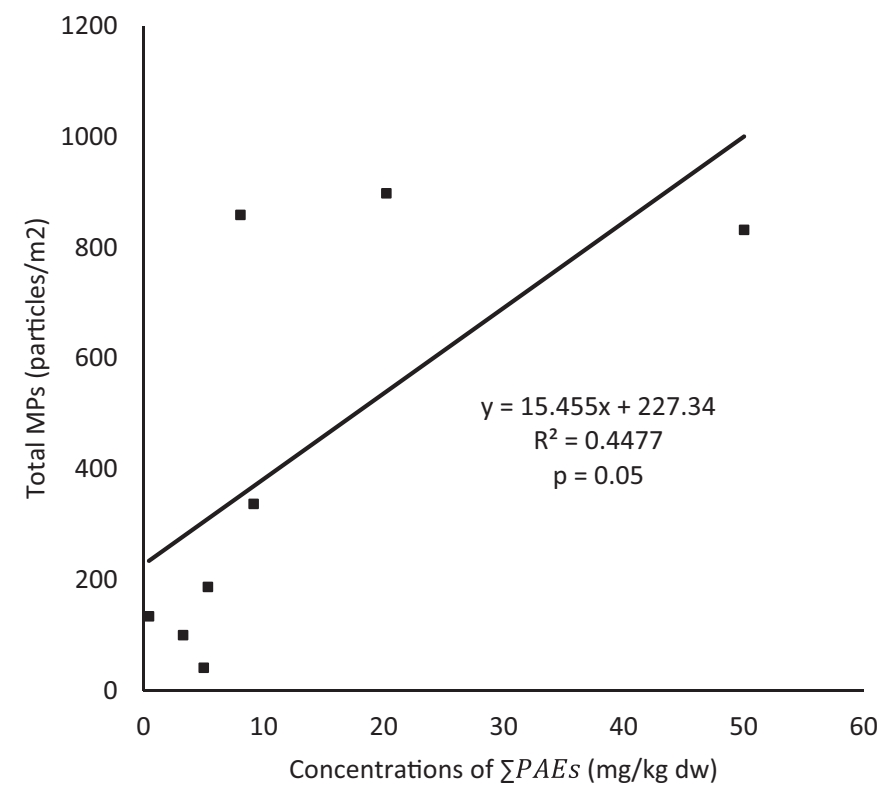

Fig. 5. Correlation between total PAEs and microplastic particles.
PAEs congeners in the environment is reported as a function of the substantial amount of leached additives transferred onto the external surfaces of microplastic debris (Kovacic and Mrklic, 2002). Thus, these mechanistic characteristics could favour the long-term, sustained release, occurrence and spatial distribution of chemical additives (phthalate esters) across the coastal beaches of the Gulf of Guinea.

\subsection{Ecotoxicological assessments associated with phthalates contamination}

The calculated phthalates pollution index (PPI) ranged between $0.10-0.53,0.04-0.42,0.06-0.16,0.02-2.78,0.10-2.24$, and $0.10-1.16$ for Elegushi, Oniru, Atican, Eleko, and Lagos lagoon aquatic ecosystems, respectively. The calculated PPI values were relatively low and mostly below 1.0 except those obtained for high waterline hard plastics from $\mathrm{KHH}, \mathrm{PRH}$, and USH sites. These results were consistent with previous studies (Zhang et al., 2018b,c; Adeogun et al., 2015), and thus give a cumulative indication of the overall PAEs concentrations in microplastic particles found in sandflat sediments across all sites.

Currently, there are very few reports that present the ecological risk assessment of phthalates in microplastics derived from aquatic sediments. The analyses in the present study indicated DEHP, DnBP and DMP were the most prevalent PAE congeners. The other three phthalates showed less detection frequency. Hence, the computation of the $\mathrm{RQ}_{m p}$ values in sediment of the coastal sites using the specified predicted no-effect concentration (PNEC) of each phthalate and the respective concentration of PAEs are presented in Fig. 6. The results indicated that the trend of $\mathrm{RQ}_{m p}$ values was DEHP $>$ DnBP $>$ DMP $>$ DEP. This distribution gradation is similar to the previous report by Zhang et al. (2018a) and Li et al. (2017). In this study, the $\mathrm{RQ}_{m p}$ value for DEHP was consistently greater than 1 across all sites for algae, and crustaceans at Elegushi and Oniru sites. These results indicate DEHP and DnBP were bioavailable and could pose high ecological and biological risks to algae and crustaceans in these ecosystems. On the contrary, the $\mathrm{RQ}_{m p}$ value calculated for DEHP ranged between 0.01 and 1 for fish at all sites except at Oniru site, thus indicating considerable medium risk for this organism. In addition, the $\mathrm{RQ}_{m p}$ value for DBP and BBZP at Elegushi, Oniru and Eleko sites were $>1$, indicating high risk for fish at these locations. Exposure of these marine organisms to these chemical additives in microplastics at these locations could pose possible effects such as congenital disabilities and unprecedented mortality rates to these aquatic faunae and flora (Corsolini et al., 2002). Further investigations are required to ascertain the possible exposure effects on these organisms.

To our knowledge, this is the first study to investigate the occurrence and distribution of microplastics-sorbed phthalate esters contamination in psammitic sediments of the tropical Atlantic Ocean, off the coast of Nigeria. Our current investigation has demonstrated that assorted polymeric types of microplastics could contribute substantial amount of phthalate esters into the coastal ecosystems of the study area, thus serving as potential sources of carcinogens and endogenous disruptors. In particular, elevated levels of DEHP could have far-reaching effects in organisms in the coastal environment, and subsequent biotransfer through the food chain and bioaccumulation in humans via consumption (Zhang et al., 2018c; Syberg et al., 2015; Li et al., 2015). Furthermore, the estrogenic phthalate plasticisers adsorbed on microplastics might be desorbed and become potentially released into the surrounding environmental matrices and living organisms (Fred-Ahmadu et al., 2020; Liu et al., 2020; Paluselli et al., 2018a,b). However, investigating the occurrence of MPs-sorbed additives and their interactions with other contaminants in microplastics requires a broader standardized analytical procedure. Methodologies including the density separation technique have the limitation of underestimating the quantity of microplastics in cases where there are higher density polymers or changes in polymer densities due to the input of additives. This could help address the knowledge gaps apropos the microplastics pollution. 
$[A]$

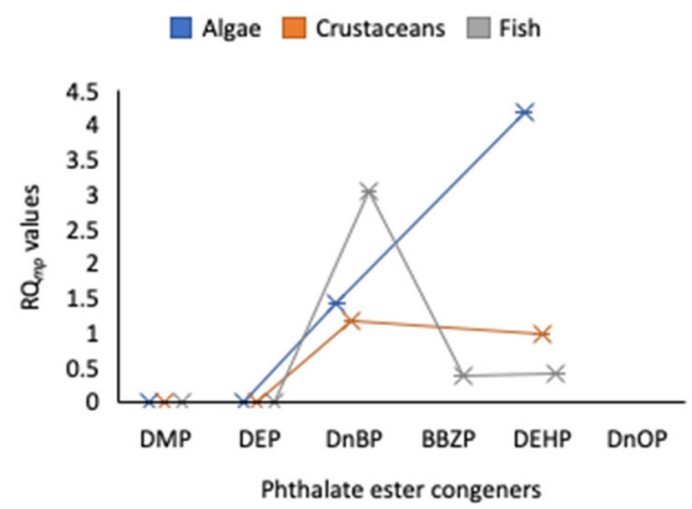

$[\mathrm{C}]$

Algae $\square$ Crustaceans $\square$ Fish

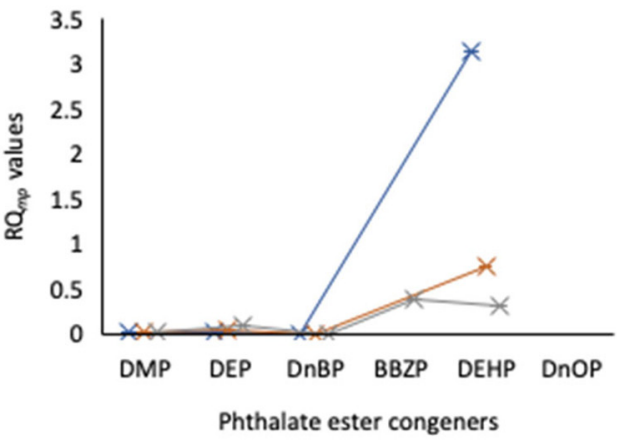

$[B]$

Algae $\square$ Crustaceans $\square$ Fish

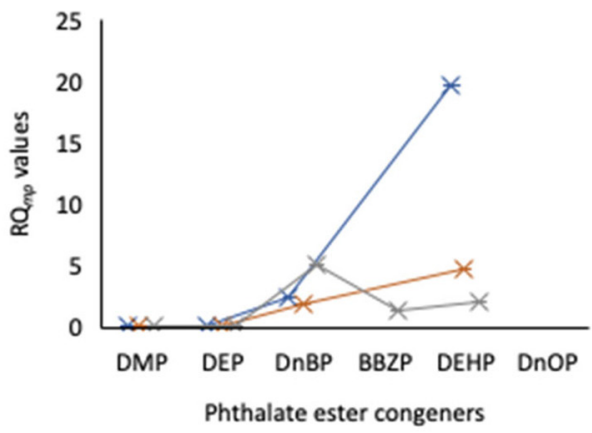

[D]

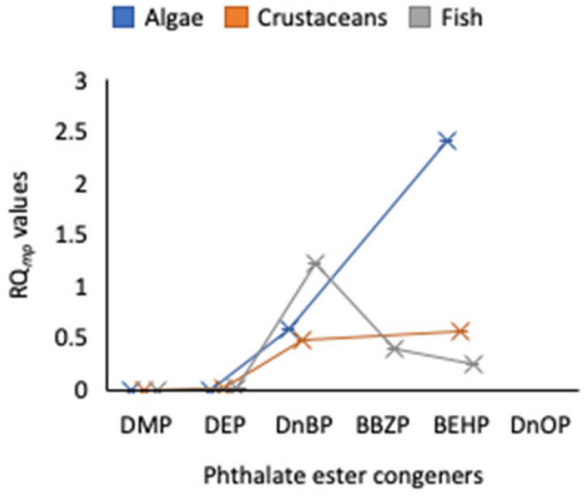

Fig. 6. Calculated risk assessment ( $\mathrm{RQ}_{m p}$ values) of plasticizer congeners found in coastal sediment samples across all sites (Elegushi [A], Oniru [B], Atican [C] and Eleko [D]).

\section{Conclusions}

This study presents a baseline data of an investigation into the occurrence, chemical and physical characterization and quantification, distribution, and environmental risk assessment of microplastic-bound phthalic esters (plasticisers) in sediment samples from major sandflat beaches along the coast of the Gulf of Guinea. The results indicate six (6) phthalate esters (dimethyl phthalate (DMP), diethyl phthalate (DEP), dibutyl phthalate (DnBP), benzylbutyl phthalate (BBZP), di(2ethylhexyl) phthalate (DEHP), and di-n-octyl phthalate (DnOP)) were detected and quantified by the GC-Q-MS in all samples analysed, across all sites in the study area. The microplastic particles distribution across coastline were heterogeneous but widespread, with the DEHP, DnBP and DMP found as the most dominant PAEs. The total concentrations of MPs-sorbed phthalates indicated variable aggregated site contents, and ranged from BDL to $164.09 \mathrm{mg} / \mathrm{kg} \mathrm{dw}$, with the sediment samples some sites having microplastics-sorbed phthalic acid esters (PAEs) with relatively elevated concentrations. The results showed MPs count, and microplastic-bound PAEs concentrations across all investigated sites may mostly be linked with land-based human-mediated activities, and the hydrological ecosystem dynamics of the coastal zone. The $\mathrm{RQ}_{m p}$ calculated from the preliminary ecological risk assessment of PAEs showed the di(2-ethylhexyl) phthalate and DnBP might present high to medium biological risks to algae, crustaceans, and fish in these ecosystems. Further investigation is necessary to further our understanding concerning the bioavailability and mobility of PAEs in aquatic ecosystems, and the adverse effects on marine organisms in these coastal zones.

\section{CRediT authorship contribution statement}

Nsikak U. Benson:Conceptualization, Data curation, Formal analysis, Investigation, Supervision, Writing - original draft, Writing - review \& editing.Omowunmi H. Fred-Ahmadu:Conceptualization, Data curation, Formal analysis, Investigation, Writing - review \& editing.

\section{Declaration of competing interest}

The authors declare that we have no known competing financial interest that could have influenced the work presented in this paper.

\section{Acknowledgements}

This work was financially supported by Covenant University Research Seed Grant, and the authors wish to acknowledge the assistance and approval provided by Prof. AAA. Atayero, the Vice-Chancellor, Covenant University, Ota, Nigeria. The authors appreciate the analytical support by Dr. Bolade Oladotun. 


\section{Appendix A. Supplementary data}

Supplementary data to this article can be found online at https://doi. org/10.1016/j.scitotenv.2020.139013.

\section{References}

Adeogun, A.O., Ibor, O.R., Omogbemi, E.D., Chukwuka, A.V., Adegbola, R.A., Adewuyi, G.A., Arukwe, A., 2015. Environmental occurrence and biota concentration of phthalate esters in Epe and Lagos Lagoons, Nigeria. Mar. Environ. Res. 108, 24-32.

Adesina, F.A., Odekunle, T.O., Ajayi, O., Eludoyin, O., Babatimehin, O., Dami, A., Moruf, S., Aloba, O., Margaret, O., Adetiloye, O.S., 2008. Adaptation strategies of action for Nigeria. A Working Document Prepared for the Special Climate Change Unit of the Federal Ministry of Environment, Housing and Development, Abuja. Heinrich Boell Stiftung, Nigeria.

Agency for Toxic Substances and Disease Registry (ATSDR), 2001. Toxicological Profile for Di-n-butyl Phthalate. Update. U.S. Department of Health and Human Services, Public Health Service, Atlanta, GA http://www.atsdr.cdc.gov/toxprofiles/tp135.pdf.

Agency for Toxic Substances and Disease Registry (ATSDR), 2002. Toxicological Profile for Di(2-ethylhexyl)phthalate (DEHP). U.S. Department of Health and Human Services, Public Health Service, Atlanta, GA http://www.atsdr.cdc.gov/toxprofiles/tp9.pdf.

Agency for Toxic Substances and Disease Registry (ATSDR), 2014. ATSDR Tox Profiles. Di (2-ethylhexyl) phthalate. Available from, as of Dec 23, 2014. http://www.atsdr.cdc. gov/toxprofiles/index.asp.

Ajao, E.A., Anurigwo, S., 2002. Land-based sources of pollution in the Niger Delta, Nigeria. AMBIO: A Journal of the Human Environment 31 (5), 442-445. https://doi.org/ 10.1579/0044-7447-31.5.442.

Alimi, O.S., Budarz, J.F., Hernandez, L.M., et al., 2018. Microplastics and nanoplastics in aquatic environments: aggregation, deposition, and enhanced contaminant transport. Environ. Sci. Technol. 52 (4), 1704-1724.

Andrady, A.L., 2011. Microplastics in the marine environment. Mar. Pollut. Bull. 62, 1596-1605.

Arbuckle, T.E., Fisher, M., MacPherson, S., Lang, C., Provencher, G., LeBlanc, A., Hauser, R., Feeley, M., Ayotte, P., Neisa, A., Ramsay, T., Tawagi, G., 2016. Maternal and early life exposure to phthalates: the plastics and personal-care products use in pregnancy (P4) study. Sci. Total Environ. 551-552, 344-356. https://doi.org/10.1016/j. scitotenv.2016.02.022.

Arfaeinia, H., Fazlzadeh, M., Taghizadeh, F., Saeedi, R., Spitz, J., Dobaradaran, S., 2019 Phthalate acid esters (PAEs) accumulation in coastal sediments from regions with different land use configuration along the Persian Gulf. Ecotoxicol. Environ. Saf. 169, 496-506. https://doi.org/10.1016/j.ecoenv.2018.11.033.

Arthur, C., Baker, J., Bamford, H., 2009. Proceeding of International Research Workshop on the Occurrence, Effects, and Fate of Microplastic Marine Debris. September 9-11, 2008. NOAA Technical Memorandum NOS-OR\&R-30.

Avio, C.G., Gorbi, S., Regoli, F., 2017. Plastics and microplastics in the oceans: from emerging pollutants to emerged threat. Mar. Environ. Res. 128, 2-11.

Awosika, L.F., 1995. Impacts of global climate change and sea level rise on coastal resources and energy development in Nigeria. In: Umolu, J.C. (Ed.), Proc. Global Climate Change-Impacts and Energy Development. Damtech Nigeria Limited, Nigeria.

Awosika, L.F., Folorunsho, R., 2006. Climate change and impact on the coastal environment of Nigeria. In: Ivbijaro, M.F., Akintola, F., Okechukwu, R.U. (Eds.), Sustainable Environmental Management in Nigeria. Mattivi Production, Nigeria (465 pp.).

Barnes, D.K.A., Galgani, F., Thompson, R.C., Barlaz, M., 2009. Accumulation and fragmentation of plastic debris in global environments. Philos. Trans. R. Soc. Lond. Ser. B Biol. Sci. 364, 1985-1998.

Benjamin, S., Masai, E, Kamimura, N., Takahashi, K, Anderson, R.C., Faisal, P.A., 2017 Phthalates impact human health: epidemiological evidences and plausible mechanism of action. J. Hazard. Mater. 340, 360-383. https://doi.org/10.1016/J. JHAZMAT.2017.06.036.

Benson, N.U., 2010a. National priorities for implementing adaptation to climate in Nigeria. IOC-UNESCO Workshop Series for Adaptation to Climate Change in Africa. A Technical Report of IOC-UNESCO, France (20p).

Benson, N.U., 2010b. Nigeria's progress in adapting to climate change on oceans and coasts. A Technical Report Prepared for the Intergovernmental Oceanographic Committee-UNESCO 50th Anniversary.

Benson, N.U., Essien, J.P., Asuquo, F.E., Eritobor, A.L., 2014. Occurrence and distribution of polycyclic aromatic hydrocarbons in surface microlayer and subsurface seawater of Lagos Lagoon, Nigeria. Environ. Monit. Assess. 186, 5519-5529. https://doi.org/ 10.1007/s10661-014-3800-z.

Benson, N.U., Adedapo, A.E., Eritobor, A.L., Udosen, E.D., 2015. Total dissolved inorganic carbon and physicochemical characteristics of surface microlayer and upper mixed layer water from Lagos Lagoon, Nigeria. Global NEST Journal 17, 334-343.

Benson, N.U., Udosen, E.D., Essien, J.P., Anake, W.U., Adedapo, A.E., Akintokun, O.A., FredAhmadu, O.H., Olajire, A.A., 2017. Geochemical fractionation and ecological risks assessment of benthic sediment-bound heavy metals from coastal ecosystems off the Equatorial Atlantic Ocean. International Journal of Sediment Research 32 (3), 410-420. https://doi.org/10.1016/j.ijsrc.2017.07.007.

Benson, N.U., Adedapo, A.E., Fred-Ahmadu, O.H., Williams, A.B., Udosen, E.D., Ayejuyo, O.O., Olajire, A.A., 2018. New ecological risk indices for evaluating heavy metals contamination in aquatic sediment: a case study of the Gulf of Guinea. Reg. Stud. Mar. Sci. 18, 44-56. https://doi.org/10.1016/j.rsma.2018.01.004.

BKH Consulting Engineers, 2000. Annex 13: list of 146 substances with endocrine disruption classifications prepared in the expert meeting. In Towards the Establishment of a Priority List of Substances for Further Evaluation of their Role in Endocrine
Disruption. Delft, The Netherlands http://ec.europa.eu/environment/docum/pdf/ bkh_annex_13.pdf.

Bosker, T., Guaita, L., Behrens, P., 2018. Microplastic pollution on Caribbean beaches in the Lesser Antilles. Mar. Pollut. Bull. 133, 442-447. https://doi.org/10.1016/j. marpolbul.2018.05.060.

Botham, C., Holmes, P., 2005. Chemicals Purported to be Endocrine Disrupters: A Compilation of Published Lists. MRC Institute for Environment and Health.

Calafat, A.M., McKee, R.H., 2006. Integrating biomonitoring exposure data into the risk assessment process: phthalates [diethyl phthalate and di(2-ethylhexyl) phthalate] as a case study. Environ. Health Perspect. 114 (11), 1783-1789.

Calvert, P.D., Billingham, N.C., 1979. Loss of additives from polymers: a theoretical model. J. Appl. Polym. Sci. 24, 357-370.

Camacho, M., Herrera, A., Gómez, M., Acosta-Dacal, A., Martínez, I., Henríquez-Hernández L.A., Luzardo, O.P., 2019. Organic pollutants in marine plastic debris from Canary Islands beaches. Sci. Total Environ. 662, 22-31. https://doi.org/10.1016/j. scitotenv.2018.12.422.

Chen, C.F., Chen, C.W., Ju, Y.R., Dong, C.D., 2017. Determination and assessment of phthalate esters content in sediments from Kaohsiung Harbor, Taiwan. Mar. Pollut. Bull. 124 (2), 767-774.

Colacino, J.A., Harris, T.R., Schecter, A., 2010. Dietary intake is associated with phthalate body burden in a nationally representative sample. Environ. Health Perspect. 118 (7), 998-1003.

Cole, M., Lindeque, P., Halsband, C., Galloway, T.S., 2011. Microplastics as contaminants in the marine environment: a review. Mar. Pollut. Bull. 62, 2588-2597. https://oi.org/ 10.1016/j.marpolbul.2011.09.025.

Commission Regulation (EU), No 10/2011 of 14 January 2011 on plastic materials and articles intended to come into contact with food, Off. J. Eur. J. L 12.

Corsolini, S., Romeo, T., Ademollo, N., Greco, S., Focardi, S., 2002. POPs in key species of marine Antarctic ecosystem. Microchem. J. 73, 187-193.

Corcoran, P.L., Biesinger, M.C., Grifi, M., 2009. Plastics and beaches: a degrading relationship. Mar. Pollut. Bull. 58, 80-84.

Cox, K.D., Covernton, G.A., Davies, H.L., Dower, J.F., Juanes, F., Dudas, S.E., 2019. Human consumption of microplastics. Environ. Sci. Technol. 53 (12), 7068-7074. https:// doi.org/10.1021/acs.est.9b01517.

Diamanti-Kandarakis, E., Bourguignon, J.P., Giudice, L.C., Hauser, R., Prins, G.S., Soto, A.M., Zoeller, R.T., Gore, A.C., 2009. Endocrine-disrupting chemicals: an Endocrine Society scientific statement. Endocr. Rev. 30 (4), 293-342.

Directive 2013/39/EU of, 2013. The European Parliament and of The Council of 12 August 2013 amending Directives 2000/60/EC and 2008/105/EC as regards priority substances in the field of water policy. Off. J. Eur. J. 226, 1-17 L

EC, 2003. European Commission Technical Guidance Document in Support of Commission Directive 93/67/EEC on Risk Assessment for New Notified Substances and Commission Regulation (EC) No. 1488/94 on Risk Assessment for Existing Substance, Part II (Brussels, Belgium).

Eriksen, M., Mason, S., Wilson, S., et al., 2013. Microplastic pollution in the surface waters of the Laurentian Great Lakes. Mar. Pollut. Bull. 77 (1-2), 177-182.

EU Parliament, 2008. DIRECTIVE 2008/105/EC of the European Parliament and of the Council of 16 December 2008 on Environmental Quality Standards in the Field of Water Policy. Off. J. Eur. Union https://eur-lex.europa.eu/eli/ dir/2008/105/2013-09-13.

Fasano, E., Cirillo, T., Esposito, F., Lacorte, S., 2015. Migration of monomers and plasticizers from packed foods and heated microwave foods using QuEChERS sample preparation and gas chromatography/mass spectrometry. LWT - Food Sci. Technol. 64 (2015) 1015-1021. https://doi.org/10.1016/J.LWT.2015.06.066.

Fred-Ahmadu, O.H., Bhagwat, G., Oluyoye, I., Benson, N.U., Ayejuyo, O.O., Palanisami, T. 2020. Interaction of chemical contaminants with microplastics: principles and perspectives. Sci. Total Environ. 706, 135978. https://doi.org/10.1016/j. scitotenv.2019.135978.

French, G.T., Awosika, L.F., Ibe, C.E., 1995. Sea level rise and Nigeria: potential impacts and consequences. J. Coast. Res. 14 (Special Issue), 224-242.

Galloway, T.S., 2015. Micro- and nano-plastic and human health. In: Bergmann, M. Gutow, L., Klages, M. (Eds.), Marine Anthropogenic Litter. Springer, Cham, pp. 343-366. https://doi.org/10.1007/978-3-319-16510-3_13.

Gao, D.-W., Wen, Z.-D., 2016. Phthalate esters in the environment: a critical review of their occurrence, biodegradation, and removal during wastewater treatment processes. Sci. Total Environ. 541, 986-1001. https://doi.org/10.1016/J.SCITOTENV. 2015.09.148.

Genuis, S.J., Beesoon, S., Lobo, R.A., Birkholz, D., 2012. Human elimination of phthalate compounds: blood, urine, and sweat (BUS) study. Sci. World J. https://doi.org/ 10.1100/2012/615068.

Gray Jr., L.E., Wilson, V.S., Stoker, T., Lambright, C., Furr, J., Noriega, N., Howdeshell, K., Ankley, G.T., Guillette, L., 2006. Adverse effects of environmental antiandrogens and androgens on reproductive development in mammals. Int J. Androl. 29 (1), 96-104.

Gray, A.D., Weinstein, J.E., 2017. Size- and shape-dependent effects of microplastic particles on adult dagger blade grass shrimp (Palaemonetes pugio). Environ. Toxicol. Chem. 36 (11), 3074-3080.

Guo, Y., Zhang, Z., Liu, L., Li, Y., Ren, N., Kannan, K., 2012. Occurrence and profiles of phthalates in foodstuffs from China and their implications for human exposure J. Agric. Food Chem. 60, 6913e6919.

Hazardous Products Act (HPA), 2010. Phthalates Regulations, Ottawa, Canada. https:// laws-lois.justice.gc.ca/eng/acts/H-3.

Hernandez, L.M., Yousefi, N., Tufenkji, N., 2017. Are there nanoplastics in your personal care products? Environ. Sci. Tech. Let. 4 (7), 280-285.

Hidalgo-Ruz, V., Gutow, L., Thompson, R.C., et al., 2012. Microplastics in the marine environment: a review of the methods used for identification and quantification. Environ. Sci. Technol. 46 (6), 3060-3075.

Holahan, M.R., Smith, C.A., 2015. Phthalates and neurotoxic effects on hippocampal network plasticity. NeuroToxicology 48, 21-34. 
IARC, 2000. Monograph on the evaluation of carcinogenic risk to humans: some industria chemicals, di(2-ethylhexyl) phthalate. IARC Monogr 77, 41-148.

IARC, 2014. Monographs on the Evaluation of the Carcinogenic Risk of Chemicals to Man Available from, as of Dec 23, 2014. http://monographs.iarc.fr/ENG/Classification/ index.php.

Ibe, A.C., 1990. Adjustments to the impact of sea level rise along the West and Central African coasts. In: Titus, J.G. (Ed.), Changing Climate and the Coast. Proceedings of the First IPCC CZMS Workshop, Miami, 27 November-1 December 1989 vol. 2. Environmental Protection Agency, Washington, DC, USA, pp. 3-12.

Jeong, C.B., Kang, H.M., Lee, Y.H., et al., 2018. Nanoplastic ingestion enhances toxicity of persistent organic pollutants (POPs) in the monogonont rotifer Brachionus koreanus via multixenobiotic resistance (MXR) disruption. Environ. Sci. Technol. 52 (19), $11411-11418$

Jiménez-Skrzypek, G., González-Sálamo, J., Varela-Martínez, D.A., et al., 2019. Analysis of phthalic acid esters in sea water and sea sand using polymer-coated magnetic nanoparticles as extraction sorbent. J. Chromatogr. A https://doi.org/10.1016/j. chroma.2019.460620.

Kang, M.J., Yang, F., Ren, H., Zhao, W.Y., Zhao, Y., Li, L.J., Yan, Y., Zhang, Y.J., Lai, S.C., Zhang Y.Y., Yang, Y., Wang, Z.F., Sun, Y.L., Fu, P.Q., 2017. Influence of continental organic aerosols to the marine atmosphere over the East China Sea: insights from lipids, PAHs and phthalates. Sci. Total Environ. 607, 339-350.

Katsikantami, I., Sifakis, S., Tzatzarakis, M.N., Vakonaki, E., Kalantzi, O.-I., Tsatsakis, A.M., Rizos, A.K., 2016. A global assessment of phthalates burden and re- lated links to health effects. Environ. Int. 97, 212-236. https://doi.org/10.1016/J. ENVINT.2016.09.013.

Kavlock, R.J., Daston, G.P., DeRosa, C., Fenner-Crisp, P., Gray, L.E., Kaattari, S., Lucier, G., Luster, M., Mac, M.J., Maczka, C., et al., 1996. Research needs for the risk assessment of health and environmental effects of endocrine disruptors: a report of the U.S. EPA-sponsored workshop. Environ. Health Perspect. 104 (Suppl. 4), 715-740.

Kolandhasamy, P., Su, L., Li, J.N., et al., 2018. Adherence of microplastics to soft tissue of mussels: a novel way to uptake microplastics beyond ingestion. Sci. Total Environ. $610,635-640$

Kovacic, T., Mrklic, Z., 2002. The kinetic parameters for the evaporation of plasticizers from plasticized poly(vinyl chloride). Thermochim. Acta 381, 49-60.

Lechner, A., Keckeis, H., Lumesberger-Loisl, F., et al., 2014. The Danube so colourful: a potpourri of plastic litter outnumbers fish larvae in Europe's second largest river. Environ. Pollut. 188, 177-181.

Lee, J.H., Koo, J.G., Keum, Y.H., Park, K.H., Choi, S.H., Kang, J.C., 2009. Effects of dibutyl phthalate and di-ethylhexyl phthalate on acetylcholinesterase activity in bagrid catfish, Pseudobagrus fulvidraco (Richardson). J. Appl. Ichthyol. 25, 771-775.

Li, J.N., Yang, D.Q., Li, L., Jabeen, K., Shi, H.H., 2015. Microplastics in commercial bivalves from China. Environ. Pollut. 207, 190-195.

Li, R.L., Liang, J., Gong, Z.B., Zhang, N.N., Duan, H.L., 2017. Occurrence, spatial distribution, historical trend and ecological risk of phthalate esters in the Jiulong River, Southeast China. Sci. Total Environ. 580, 388-397.

Li, J., Xia, W., Wu, C., Zhao, H., Zhou, Y., Wei, J., Ji, F., Luan, H., Xu, S., Cai, Z., 2019. Variations of phthalate exposure and metabolism over three trimesters. Environ. Pollut. 251, 137-145. https://doi.org/10.1016/j.envpol.2019.04.085.

Liu, P., Zhan, X., Wu, X., Li, J., Wang, H., Gao, S., 2020. Effect of weathering on environmental behavior of microplastics: properties, sorption and potential risks. Chemosphere 242, 125193. https://doi.org/10.1016/j.chemosphere.2019.125193.

López-Carrillo, L., Hernández-Ramírez, R.U., Calafat, A.M., Torres-Sánchez, L., GalvánPortillo, M., Needham, L.L., et al., 2010. Exposure to phthalates and breast cancer risk in northern Mexico. Environ. Health Perspect. 118 (4), 539.

Magni, S., Gagne, F., Andre, C., et al., 2018. Evaluation of uptake and chronic toxicity of virgin polystyrene microbeads in freshwater zebra mussel Dreissena polymorpha (Mollusca: Bivalvia). Sci. Total Environ. 631-632, 778-788.

von Moos, N., Burkhardt-Holm, P., Kohler, A., 2012. Uptake and effects of microplastics on cells and tissue of the blue mussel Mytilus edulis L. after an experimental exposure. Environ. Sci. Technol. 46 (20), 11327-11335.

National Research Council, 2008. Phthalates and Cumulative Risk Assessment: The Tasks Ahead. The National Academies Press, Washington, DC http://www.nap.edu/catalog/ 12528.html.

Net, S., et al., 2015. Occurrence, fate, behavior and ecotoxicological state of phthalates in different environmental matrices. Environ. Sci. Technol. 49, 4019-4035.

NIH, 2019. Bis(2-ethylhexyl) Phthalate. National Institutes of Health, U.S. National Library of Medicine, National Center for Biotechnology Information Available at. https:// pubchem.ncbi.nlm.nih.gov/compound/Bis_2-ethylhexyl_-phthalate, Accessed date: 28 December 2019.

Nizzetto, L., Futter, M., Langaas, S., 2016. Are agricultural soils dumps for microplastics of urban origin? Environ. Sci. Technol. 50, 10777-10779.

NOAA, 2018. What are microplastics?. [WWW Document]. Natl. Ocean. Atmos. Adm. URL https://oceanservice.noaa.gov/facts/microplastics.html, Accessed date: 7 December 2019 .

NOAA, Administration NOAA, 2015. Microplastics Marine Debris. Marine Debris Program, Office of Response and Restoration, National Ocean Service, USA https:// marinedebris.noaa.gov/sites/default/files/MicroplasticsOnePager_0.pdf, Accessed date: 7 December 2019.

NOAA, National Oceanic and Atmospheric Administration, 2016. Glossary - NOAA Shoreline. Retrieved November 15, 2019, from. https://shoreline.noaa.gov/glossary.html.

Otake, T., Yoshinaga, J., Yanagisawa, Y., 2004. Exposure to phthalate esters from indoor environment. J. Expo. Anal. Environ. Epidemiol. 14 (7), 524-528.

Paluselli, A., Aminot, Y., Galgani, F., Net, S., Sempéré, R., 2018a. Occurrence of phthalate acid esters (PAEs) in the northwestern Mediterranean Sea and the Rhone River. Prog. Oceanogr. 163, 221-231. https://doi.org/10.1016/j.pocean.2017.06.002.

Paluselli, A., Fauvelle, V., Galgani, F., Sempéré, R., 2018b. Phthalate release from plastic fragments and degradation in seawater. Environ. Sci. Technol. 53 (1), 166-175.
Patisaul, H.B., Adewale, H.B., 2009. Long-term effects of environmental endocrine disruptors on reproductive physiology and behavior. Front. Behav. Neurosci. 3, 10.

Pérez-Lobato, R., Mustieles, V., Calvente, I., Jiménez-Díaz, I., Ramos, R., Caballero- Casero, N., López-Jiménez, F.J., Rubio, S., Olea, N., Fernández, M.F., 2016. Exposure to Bisphenol A and behavior in school-age children. NeuroToxicology 53, 12-19.

Prata, J.C., 2018. Airborne microplastics: Consequences to human health? Environ. Pollut. 234, 115-126 https://doi.org/10.1016/j.envpol.2017.11.043.

Prata, J.C., da Costa, J.P., Lopes, I., Duarte, A.C., Rocha-Santos, T., 2020. Environmental exposure to microplastics: an overview on possible human health effects. Sci. Total Environ. 702, 134455. https://doi.org/10.1016/j.scitotenv.2019.134455

Qiu, Q., Peng, J., Yu, X., Chen, F., Wang, J., Dong, F., 2015. Occurrence of microplastics in the coastal marine environment: first observation on sediment of China. Mar. Pollut. Bull. 98 (1), 274-280.

Rahman, M., Brazel, C.S., 2004. The plasticizer market: an assessment of traditional plasticizers and research trends to meet new challenges. Prog. Polym. Sci. 29, 1223-1248. https://doi.org/10.1016/J.PROGPOLYMSCI.2004.10.001.

Ramirez, M.M.B., Caamal, R.D., von Osten, J.R., 2019. Occurrence and seasonal distribution of microplastics and phthalates in sediments from the urban channel of the Ria and coast of Campeche, Mexico. Sci. Total Environ. 672, 97-105. https://doi.org/ 10.1016/j.scitotenv.2019.03.472.

Ramzi, A., Gireeshkumar, T.R., Habeeb Rahman, K., Manu, M., Balachandran, K.K., Chacko, J., Chandramohanakumar, N., 2018. Distribution and contamination status of phthalic acid esters in the sediments of a tropical monsoonal estuary, Cochin - India. Chemosphere 210 (2018), 232-238. https://doi.org/10.1016/J.CHEMOSPHERE.2018. 06.182.

Retama, I., Jonathan, M.P., Shruti, V.C., Velumani, S., Sarkar, S.K., Roy, Priyadarsi D. Rodríguez-Espinosa, P.F., 2016. Microplastics in tourist beaches of Huatulco Bay, Pacific coast of southern Mexico. Mar. Pollut. Bull. 113, 530-535.

Reyes, J.M., Price, P.S., 2018. Temporal trends in exposures to six phthalates from biomonitoring data: implications for cumulative risk. Environ. Sci. Technol. 52 (21), 12475-12483.

Ribeiro, F., O'Brien, J.W., Galloway, T., et al., 2019. Accumulation and fate of nano- and micro-plastics and associated contaminants in organisms. Trac-Trend. Anal. Chem. 111, 139-147.

Rocha, B.A., et al., 2017. Urinary concentrations of 25 phthalate metabolites in Brazilian children and their association with oxidative DNA damage. Sci. Total Environ. 586, 152-162.

Rochman, C.M., Kross, S.M., Armstrong, J.B., et al., 2015. Scientific evidence supports a ban on microbeads. Environ. Sci. Technol. 49 (18), 10759-10761.

Sathyanarayana, S., 2008. Phthalates and children's health. Current Problems in Pediatric and Adolescent Health Care 38 (2), 34-49.

SCCP (Scientific Committee on Consumer Products), 2007. Opinion on Phthalates in Cosmetic Products Opinion Adopted at the 11th Plenary Meeting of 21 March 2007, Brussels, SCCP/1016/06 (19 pp.).

Scopetani, C. Cincinelli, A. Martellini, T., Lombardini, E, Ciofini, A., Fortunati, A, Pasquali, V., Ciattini, S., Ugolini, A., 2018. Ingested microplastic as a two-way transporter for PBDEs in Talitrus saltator. Environ. Res. 167, 411-417. https://doi.org/10.1016/J. ENVRES.2018.07.030.

Sha, Y.J., Xia, X.H., Yang, Z.F., Huang, G.H., 2007. Distribution of PAEs in the middle and lower reaches of the Yellow River, China. Environ. Monit. Assess. 124, 277-287.

Sun, X., Liang, J., Zhu, M., Zhao, Y., Zhang, B., 2018. Microplastics in seawater and zooplankton from the Yellow Sea. Environ. Pollut. 242, 585-595. https://doi.org/ 10.1016/J.ENVPOL.2018.07.014

Syberg, K., Khan, F.R., Selck, H., Palmqvist, A., Banta, G.T., Daley, J., et al., 2015. Microplastics: addressing ecological risk through lessons learned. Environ. Toxicol. Chem. 34, 945-953.

Tanaka, K., Takada, H., Yamashita, R., Mizukawa, K., Fukuwaka, M.-A., Watanuki, Y., 2013. Accumulation of plastic-derived chemicals in tissues of seabirds ingesting marine plastics. Mar. Pollut. Bull. 69 (1-2), 219-222.

Thompson, R.C., Olsen, Y., Mitchell, R.P., Davis, A., Rowland, S.J., John, A.W.G., McGonigle, D., Russell, A.E., 2004. Lost at sea: where is all the plastic? Science 304, 838.

Tomlinson, D.C., Wilson, J.G., Harris, C.R., Jeffrey, D.W., 1980. Problems in the assessment of heavy metals levels in estuaries and the formation of pollution index. Helgolander Wissenschaff Meeresuntersuchungen 33, 566-569.

U.S. Consumer Product Safety Commission (CPSC), 2017. CPSC Prohibits Certain Phthalates in Children's Toys and Child Care Products, https://www.cpsc.gov/Newsroom/News-Releases/2018/CPSC-Prohibits-Certain-Phthalates-in-Childrens-Toysand-Child-Care-Products.

U.S. Environmental Protection Agency, 2012. Phthalates: Action Plan. http://www.epa. gov/pbt/.

U.S. Environmental Protection Agency, 2017. Biomonitoring Phthalates: America's Children and the Environment.Available at. https://www.epa.gov/sites/production/files/ 2017-08/documents/phthalates updates live file 508 0.pdf (accessed 16-12-2019).

USEPA, 1982. Office of the Federal Registration (OFR), 40 CFR Part 423. Available ate. https://www.govinfo.gov/content/pkg/CFR-2014-title40-vol29/pdf/CFR-2014title40-vol29-part423-appA.pdf.

Vianello, A., Jensen, R.L., Liu, L., Vollertsen, J., 2019. Simulating human exposure to indoor airborne microplastics using a breathing thermal manikin. Sci. Rep. 9, 8670. https:// doi.org/10.1038/s41598-019-45054-w.

Wang, J., Luo, Y., Teng, Y., Ma, W., Christie, P., Li, Z., 2013. Soil contamination by phthalate esters in Chinese intensive vegetable production systems with different modes of use of plastic film. Environ. Pollut. 180, 265-273.

Wang, R., Tang, J., Xie, Z., Mi, W., Chen, Y., Wolschke, H., et al., 2015. Occurrence and spatial distribution of organophosphate ester flame retardants and plasticizers in 40 rivers draining into the Bohai Sea, north China. Environ. Pollut. 198, 172-178.

Wang, W., Ndungu, A.W., Li, Z., Wang, J., 2017. Microplastics pollution in inland freshwaters of China: a case study in urban surface waters of Wuhan, China. Sci. Total Environ. 575, 1369-1374. 
Wang, W., Ge, J., Yu, X., Li, H., 2019. Environmental fate and impacts of microplastics in soil ecosystems: Progress and perspective. Sci. Total Environ. 708, 134841. https:// doi.org/10.1016/j.scitotenv.2019.134841.

Wensing, M., Uhde, E., Salthammer, T., 2005. Plastics additives in the indoor environment - flame retardants and plasticizers. Sci. Total Environ. 339, 19-40.

Xu, Y., Cohen Hubal, E.A., Clausen, P.A., Little, J.C., 2009. Predicting residential exposure to phthalate plasticizer emitted from vinyl flooring: a mechanistic analysis. Environ. Sci. Technol. 43, 2374e2380.

Xu, Z., Xiong, X., Zhao, Y., Xiang, W., Wu, C., 2020. Pollutants delivered every day: phthalates in plastic express packaging bags $\mathrm{T}$ and their leaching potential. J. Hazard. Mater. 384, 121282. https://doi.org/10.1016/j.jhazmat.2019.121282.

Yu, X.B., Peng, J.P., Wang, J.D., Wang, K., Bao, S.W., 2016. Occurrence of microplastics in the beach sand of the Chinese inner sea: the Bohai Sea. Environ. Pollut. 214, 722-730.

Zarfl, C., Fleet, D., Fries, E., et al., 2011. Microplastics in oceans. Mar. Pollut. Bull. 62 (8), 1589-1591.

Zhang, Z.-M., Zhang, H.-H., Zou, Y.-W., Yang, G.-P., 2018a. Distribution and ecotoxicological state of phthalate esters in the sea-surface microlayer, seawater and sediment of the Bohai Sea and the Yellow Sea. Environ. Pollut. 240, 235-247.
Zhang, Z.M., Zhang, H.H., Zhang, J., Wang, Q.W., Yang, G.P., 2018b. Occurrence, distribution, and ecological risks of phthalate esters in the seawater and sediment of Changjiang River Estuary and its adjacent area. Sci. Total Environ. 619-620, 93-102.

Zhang, H., Zhou, Q., Xie, Z., Zhou, Y., Tu, C., Fu, C., Mi, W., Ebinghaus, R., Christie, P., Luo, Y. 2018c. Occurrences of organophosphorus esters and phthalates in the microplastics from the coastal beaches in north China. Sci. Total Environ. 616-617, 1505-1512. https://doi.org/10.1016/j.scitotenv.2017.10.163.

Zhang Q Song J. Li, X, Peng Q Yuan, H. Li, N., Duan, L, Ma, J. 2019. Concentrations and distribution of phthalate esters in the seamount area of the Tropical Western Pacific Ocean. Mar. Pollut. Bull. 140, 107-115. https://doi.org/10.1016/j.marpolbul.2019.01.015.

Zheng, X.X., Zhang, B.T., Teng, Y.G., 2014. Distribution of phthalate acid esters in lakes of Beijing and its relationship with anthropogenic activities. Sci. Total Environ. 476477, 107-113.

Zobkov, M., Esiukova, E., 2017. Microplastics in Baltic bottom sediments: quantification procedures and first results. Mar. Pollut. Bull. 114, 724-732. 